\title{
Mechanisms of endocrine resistance and novel therapeutic strategies in breast cancer
}

\author{
Nicola Normanno ${ }^{1}$, Massimo Di Maio ${ }^{2}$, Ermelinda De Maio ${ }^{2}$, Antonella De Luca ${ }^{1}$, \\ Andrea de Matteis ${ }^{3}$, Antonio Giordano ${ }^{4}$ and Francesco Perrone ${ }^{2}$ on behalf \\ of the NCl-Naples Breast Cancer Group
}

\author{
${ }^{1}$ Cell Biology and Preclinical Models, ${ }^{2}$ Clinical Trials ${ }^{3}$ Medical Oncology C Units, INT-Fondazione Pascale, Via Mariano Semmola \\ 80131 Naples, Italy \\ ${ }^{4}$ Sbarro Institute for Cancer Research and Molecular Medicine, Department of Biology, College of Science and Technology, \\ Temple University, Philadelphia, Pennsylvania 19122, USA
}

(Requests for offprints should be addressed to N Normanno; Email: nicnorm@yahoo.com)

\begin{abstract}
Tamoxifen has been the mainstay of hormonal therapy in both early and advanced breast cancer patients for approximately three decades. The availability of novel compounds such as aromatase inhibitors (Als) and fulvestrant, with different mechanism of action, is changing the scenario of endocrine treatment of postmenopausal breast cancer patients. In this review article, we have summarized the current knowledge of the mechanisms of resistance to endocrine therapy, in order to derive information that might be useful for therapeutic intervention. We propose that resistance to endocrine therapy is a progressive, step-wise phenomenon induced by the selective pressure of hormonal agents, which leads breast cancer cells from an estrogen-dependent, responsive to endocrine manipulation phenotype to a non-responsive phenotype, and eventually to an estrogenindependent phenotype. In particular, evidence suggests for each 'action' introduced to block estrogen stimulation of breast cancer cells (i.e. treatment with anti-estrogen), there are one or more corresponding 'reactions' that tumor cells can use to escape our attempts to block their growth: estrogen hypersensitivity associated with increased transcriptional activity of estrogen receptor $\alpha(E R \alpha)$ and/or increased non-genomic activity of $E R \alpha$, estrogen supersensitivity, increased growth factor signaling, suppression of ER $\alpha$ expression and finally estrogen independence. Activation of growth factor signaling is involved in each step of this phenomenon, and might ultimately substitute estrogen in sustaining the growth and the survival of breast cancer cells. In this respect, results of pre-clinical and clinical studies with Als, fulvestrant and signaling inhibitors sustain this hypothesis. More importantly, the knowledge of the mechanisms involved in the resistance of breast cancer cells to endocrine therapy offers potential for novel therapeutic strategies.
\end{abstract}

Endocrine-Related Cancer (2005) 12 721-747

\section{Introduction}

It has long been established that estrogen is involved in the pathogenesis of breast carcinoma, and that it sustains the growth of breast cancer cells that express the receptor for this hormone. Indeed, approximately $70 \%$ of breast cancer patients are positive for estrogen receptor (ER) or progesterone receptor $(\mathrm{PgR})$ expression at diagnosis. These patients are therefore suitable candidates for hormonal therapy, which aims to block estrogen stimulation of breast cancer cells. This can be achieved by different approaches. In postmenopausal women, who are characterized by no longer exhibiting ovarian production of estrogen, ovarian suppression is not required, and medical therapy is based on the use of drugs that will: block the activity of ER such as tamoxifen or other selective estrogen receptor modulators (SERMs); induce destabilization and degradation of ER such as the selective estrogen receptor down-regulators (SERDs); 
or reduce the production of estrogen in peripheral tissues and within the tumor using aromatase inhibitors (AIs).

Tamoxifen has been the mainstay of hormonal therapy in both early and advanced breast cancer patients for approximately three decades (Early Breast Cancer Trialist Group 1998, Gradishar 2004). As a matter of fact, tamoxifen was the first target-based agent directed against a growth-promoting pathway that entered clinical practice. Almost all patients with ER-positive tumors in Western countries have been treated with this drug either as adjuvant treatment following surgery or as first-line treatment for advanced disease. However, approximately $50 \%$ of patients with advanced disease do not respond to first-line treatment with tamoxifen. Furthermore, almost all patients with metastatic disease and approximately $40 \%$ of the patients that receive tamoxifen as adjuvant therapy experience tumor relapse and die from their disease. These findings strongly suggest that mechanisms of de novo or acquired resistance to tamoxifen occur in breast cancer patients, and that this phenomenon might largely affect the efficacy of this treatment.

Results of recent clinical trials suggest that AIs have an enhanced anti-tumor effect as compared with tamoxifen, and that they might be effective in patients that are resistant to tamoxifen (Gradishar 2004, Strasser-Weippl \& Goss 2005). The rationale for use of these compounds in postmenopausal patients derives from the observation that estrogen in this set of patients is produced by aromatase in peripheral tissues and in the tumor (Johnston \& Dowsett 2003, Lonning 2004). However, the response rate to these compounds is only slightly higher as compared with tamoxifen in patients with advanced breast cancer, and mechanisms of de novo or acquired resistance to these compounds clearly affect their efficacy. The availability of different novel drugs for hormonal therapy of breast cancer, the knowledge of the mechanisms that are employed by breast cancer cells to adapt to estrogen deprivation and the generation of novel compounds that can interfere with the growth factor-driven signaling pathways involved in resistance to anti-hormonal therapy, might enable novel strategies to be designed for therapeutic intervention in ER-positive breast cancer patients. The aim of this review article is indeed to summarize the current knowledge on the mechanisms of resistance of breast cancer cells to endocrine manipulation, and the results of most recent clinical trials with novel antihormonal drugs such as AIs and fulvestrant. More importantly, we propose a model that tries to summarize the steps involved in the progressive resistance to endocrine therapy that arises in breast cancer cells following treatment with hormonal agents. We are aware that this model has some pitfalls, since it has been basically built on the results of pre-clinical studies. However, we believe that such provocative interpretation of current data on resistance to endocrine therapy might help to open the discussion on crucial points that we feel need to be addressed, and to develop novel therapeutic strategies in breast cancer patients.

\section{Mechanism of action of ER}

In order to discuss the mechanisms of resistance to hormonal therapy, we need briefly to describe the molecular pharmacology of ER. Actually, there are two different ERs, ER $\alpha$ and ER $\beta$ that are produced by distinct genes. The peculiar characteristics of ER $\beta$ will be briefly described in one of next paragraphs. If not otherwise specified, 'ER' will refer to 'ER $\alpha$ ' in the following paragraphs. Binding of estrogen to ER induces activation of the receptor. In fact, ER dissociates from heat shock proteins, and undergoes conformational changes, dimerization and phosphorylation (Osborne \& Schiff 2005). The activated ER binds to estrogen response elements (EREs) that are located upstream of estrogen-regulated genes. In this respect, it has been demonstrated that approximately $70 \%$ of estrogen-regulated genes are down-regulated following treatment with estradiol by using microarray analysis of gene expression in MCF-7 cells (Frasor et al. 2003). Many down-regulated genes are transcriptional repressors, or genes with anti-proliferative or pro-apoptotic function, whereas genes that induce cell proliferation are up-regulated. Two different domains, activating function-1 (AF-1) and AF-2, mediate positive regulation of gene expression by ER. AF-1 is at the $\mathrm{N}$-terminus of the receptor, its function is regulated by phosphorylation and it is hormoneindependent, whereas AF-2 is in the ligand-binding domain of the receptor and is hormone-dependent. The two activating domains act synergistically, although some gene promoters have been shown to be activated independently by AF-1 or AF-2 (Gronemeyer 1991, Osborne et al. 2001). Co-regulatory molecules that interact with the ER-ligand complex modulate the transcriptional activity of ER. In particular, the transcriptional activity of ER is enhanced by binding to the AF-2 domain of co-activators such as nuclear-receptor co-activator 1 (NCoA1 or SRC1), NCoA2 (TIF2) and NCoA3 (AIB1, TRAM1, RAC3 or ACTR) (McKenna et al. 1999, Leo \& Chen 2000). These proteins form large complexes that enhance ER-driven transcription by different mechanisms 


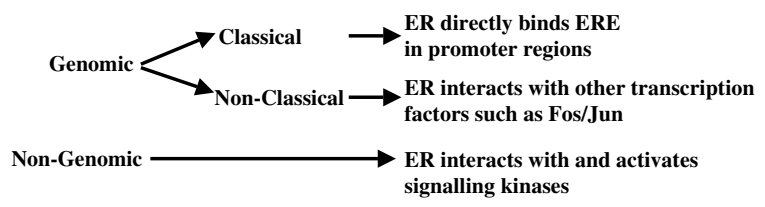

Figure 1 Modes of action of estrogen receptor (ER). ERE, estrogen response elements.

including recruitment of histone-acetyltransferase (HAT) at the promoter site. In contrast, co-repressor proteins such as nuclear-receptor co-repressor 1 (NCoR1) and NcoR2 influence ER-induced transcription at least in part by recruitment of histonedeacetylase complexes (Chen \& Evans 1995, Horlein et al. 1995).

The genomic actions of ER are profoundly affected by tamoxifen binding. In fact, tamoxifen induces in ER a conformational change that prevents binding of co-activators and therefore blocks AF-2-induced transcription (Shiau et al. 1998). These findings explain the ability of tamoxifen to function as both an antagonist and an agonist of estrogen. In fact, tamoxifen blocks the transcription of genes that depend essentially on AF-2 for gene expression. However, in AF-1-dependent genes tamoxifen can function as an agonist (Tzukerman et al. 1994, McDonnel et al. 1995). In addition, it has been shown that tamoxifen interacts with co-repressors when bound to ER, and that this mechanism is involved in the suppression of transcription (Lavinsky et al. 1998, Schiff et al. 2003). Therefore, the availability of co-regulators might be the cause of the tissue-dependent effects of tamoxifen.

The above-described mechanism is referred as the 'classical mode' of action of ER and is directly related to its ability to regulate the expression of genes that have ERE elements in the promoter region (Fig. 1). However, different mechanisms of action of ER have been demonstrated. In particular, ER has been shown to interact with other transcription factors such as the Fos-Jun complex to regulate gene expression at alternative regulatory DNA sequences such as AP-1, SP-1 and other non-defined sites (non-classical mode) (Ray et al. 1997, Kushner et al. 2000, Safe 2001). Furthermore, the ability of membrane ER $\alpha$ to interact with and/or activate several kinases including the insulin-like growth factor-1 receptor (IGF-1R), Src, phosphatidylinositol 3-kinase (PI3K), mitogenactivated protein kinase (MAPK), epidermal growth factor receptor (EGFR) and ErbB-2 has been demonstrated (non-genomic effects of ER) (Migliaccio et al. 1996, Kahlert et al. 2000, Sun et al. 2001, Chung et al. 2002, Wong et al. 2002, Schiff et al. 2004, Shou et al. 2004). The cytoplasmic kinases can also phosphorylate co-activators that can modify ER $\alpha$ activity (Bunone et al. 1996, Font de Mora \& Brown 2000, Campbell et al. 2001). Interestingly, it has been suggested that SERMs such as tamoxifen behave as estrogen agonists on these membrane effects of ER $\alpha$ (Schiff et al. 2004, Shou et al. 2004). However, membrane functions of ER depend on the levels of the above-mentioned kinases, and they might be modest in breast cancer cells that express low levels of tyrosine kinase receptors such as EGFR and ErbB-2.

The genomic and non-genomic mechanisms of action of ER are not mutually exclusive, and many interactions between these two pathways exist. For example, ER induces the expression of transcripts for both transforming growth factor $\alpha$ (TGF $\alpha)$ and amphiregulin (AR) (Saeki et al. 1991, Normanno et al. 1993). TGF $\alpha$ and AR are both able to bind and activate EGFR thus leading to activation of MAPK and AKT signaling (Salomon et al. 1995). Formation of EGFR/ErbB-2 heterodimers in cancer cells can also lead to activation of ErbB-2 that has no known ligands. MAPK and AKT pathways can be also activated by direct interaction of $E R \alpha$ with these kinases. In addition, ER $\alpha$ binds to caveolin- 1 at the cell membrane and activates specific $G$ proteins (Levin 2003). This phenomenon leads to activation of src, which in turn activates matrix metalloproteinases that cleave transmembrane precursors of heparin bindingEGF (HB-EGF), an EGFR ligand (Razandi et al. 2003). Therefore, both genomic and non-genomic activities of ER can lead to increased activation of EGFR and its downstream effectors.

Finally, it has been demonstrated that ER $\alpha$ can be phosphorylated and activated by different intracellular kinases, a process defined as ligand-independent activation (Schiff et al. 2003, Johnston 2005). In particular, ER $\alpha$ is phosphorylated at key positions (serine 118 , serine 167 and threonine 311) in the AF-1 domain and in other domains following activation of MAPK/ ERK, PI3K/AKT, p90rsk and p38 MAPK pathways, which occurs in response to various cytokines and growth factors - including ligands of EGFR or IGF-1R (Kato et al. 1995, Bunone et al. 1996, Joel et al. 1998, Campbell et al. 2001).

\section{Mechanisms of resistance to hormonal therapy}

Several different mechanisms have been hypothesized to be involved in the resistance of breast cancer cells to hormonal therapy (Table 1). These mechanisms have 
Table 1 Potential mechanisms of resistance to endocrine therapy in breast carcinoma.

Loss of expression or altered function (mutations) of ER $\alpha$ Lack of expression of $\mathrm{PgR}$ Increased expression of ER $\beta$

Metabolism of hormonal agents (CYP2D6 variants for tamoxifen)

Altered expression of co-regulators

Estrogen hypersensitivity

Estrogen supersensitivity

Increased growth factor signalling

been accurately described in excellent recent review articles, and to describe them in detail is beyond the purpose of this review (Johnston \& Dowsett 2003, Santen et al. 2003, Nicholson et al. 2004, Ring \& Dowsett 2004). Therefore, we will briefly summarize these findings in the next paragraphs in order to provide the reader with the basis for the discussion of the results of clinical trials. More importantly, we will try to draw a hypothesis that summarizes the main findings in this field, and that might be useful in the generation of novel therapeutic strategies.

Three different classes of agents are currently employed or are under investigation as anti-estrogen therapy: SERMs such as tamoxifen that have both antagonist and agonist activity; SERDs such as fulvestrant, which destabilize the receptor and induce its degradation; AIs that block the peripheral and intra-tumoral production of estrogen. As we will discuss later, the mechanisms of resistance to these three classes of compounds differ at least in part. Of course, there is a large body of literature on the resistance to tamoxifen whereas the information available for more recent drugs is limited. Therefore, we will consider each type of resistance mechanism in turn, and will try to discuss whether different types of agents might share the particular mechanism.

\section{Alterations in ER $\alpha$ and PgR expression or function}

Since expression of $E R \alpha$ is the main predictor of response to endocrine therapy, lack of expression of ER is clearly the main mechanism of de novo resistance to treatment with hormonal agents. In this respect, the absence of ER $\alpha$ gene expression has been associated with the aberrant methylation of its $\mathrm{CpG}$ islands in a significant fraction of breast cancers (Weigel \& deConinck 1993, Ottaviano et al. 1994). Recent data indicate that chromatin inactivation mediated by histone deacetylation and DNA methylation are indeed critical components of $\mathrm{ER} \alpha$ silencing in human breast cancer cells (Parl 2003). In vitro studies have shown that DNA (cytosine-5) methyltransferase (DNMT1) interacts physically with either histone deacetylase 1 (HDAC1) or histone deacetylase 2 (HDAC2) and that co-treatment with DNMT1 and HDAC inhibitors can synergistically induce $E R \alpha$ gene expression in ER $\alpha$-negative breast cancer cells (Robertson et al. 2000, Rountree et al. 2000, Yang et al. 2001). Recent findings suggest that $\mathrm{pRb} 2 / \mathrm{p} 130$ multimolecular complexes involving HDAC and DNMT can be key elements in the regulation of ER $\alpha$ gene expression (Macaluso et al. 2003). Therefore, these proteins may be viewed as promising targets for the development of novel therapeutic strategies in the treatment of breast cancer, especially for those tumors that are ER negative (Davis et al. 2000, Yang et al. 2000, 2001).

It has also been hypothesized that loss of expression of ER $\alpha$ might be responsible for acquired resistance to tamoxifen. However, it has been demonstrated that patients with expression of $E R \alpha$ and sensitivity to tamoxifen, usually do not lose expression of ER $\alpha$ following development of resistance to tamoxifen. In fact, loss of ER $\alpha$ expression has been demonstrated only in $17-28 \%$ of patients with acquired resistance to tamoxifen (Johnston et al. 1995, Gutierrez et al. 2005). In addition, approximately $20 \%$ of tamoxifenresistant patients will eventually respond to second-line treatment with AIs or fulvestrant (Howell et al. 2002, Osborne et al. 2002). These observations imply that the majority of patients with acquired resistance to tamoxifen still express ER.

Mutations of ER $\alpha$ might also affect the response to anti-estrogens. However, such mutations have rarely been found in human primary breast carcinomas, and therefore they are not likely to contribute significantly to resistance to agents that modulate the function of the receptor, such as SERMs. In addition, many of these mutations have been detected in patients that were clinically classified as ER negative (Herynk \& Fuqua 2004). Fuqua's group reported the occurrence of a single amino acid substitution changing lysine 303 to arginine mutation in 20 out of 59 hyperplastic breast lesions (Fuqua et al. 2000). Such mutation leads to a hypersensitive ER $\alpha$ that shows enhanced binding of co-activators in the presence of low estrogen levels. However, the frequency of this mutation in primary breast carcinomas needs to be explored in a larger number of patients.

$\mathrm{PgR}$ expression has recently been shown to be associated with increased benefit from adjuvant tamoxifen (Bardou et al. 2003). In particular, 
ER-positive/PgR-positive patients showed a significantly higher reduction of relative risk of recurrence and death as compared with ER-positive/PgR-negative patients. Interestingly, analysis of data from adjuvant treatment of postmenopausal breast cancer patients also shows that AIs are impressively more effective than tamoxifen in ER-positive/PgR-negative patients (Dowsett 2003). In this respect, it has been hypothesized that loss of $\mathrm{PgR}$ expression might reflect a sustained activation of growth factor signaling pathways (Osborne et al. 2005). In fact, it has been demonstrated that activation of the PI3K/AKT pathway - which might be determined by either IGF-1R or EGFR/ErbB-2 tyrosine kinases in breast cancer cells - downregulates the transcription of the $\mathrm{PgR}$ gene (Cui et al. 2003). Increased growth factor signaling might also lead to increased non-genomic activities of $E R \alpha$, which are enhanced following tamoxifen-binding to the receptor, as we will discuss below. This hypothesis might explain the superiority of AIs over tamoxifen in this subset of patients.

\section{ER $\beta$}

The role of ER $\beta$ in resistance to endocrine therapy has not been completely elucidated yet. In fact, it has been demonstrated that when ER $\beta$ is bound to tamoxifen, raloxifen or the anti-estrogen ICI 164384 , transcription of AP-1-dependent genes is increased (Paech et al. 1997). In addition, the levels of ER $\beta$ transcripts were found to be approximately 2-fold higher than $\mathrm{ER} \alpha$ levels in tamoxifen-resistant patients as compared with tamoxifen-sensitive tumors (Speirs et al. 1999). Taken together, these findings might suggest a role for ER $\beta$ in the resistance to endocrine therapy. However, other studies have demonstrated that ER $\beta$ has a negative effect on ER $\alpha$-promoted transcription (Hall \& McDonnell 1999, Pettersson et al. 2000). Finally, a recent report has shown that the levels of ER $\beta$ mRNAs are not correlated with response or resistance to toremifene in breast cancer patients that received hormonal therapy as neoadjuvant treatment (Cappelletti et al. 2004). Therefore, no conclusions on the role of ER $\beta$ in the resistance to endocrine therapy can be drawn at this point.

\section{Pharmacogenomic mechanisms}

Metabolism of tamoxifen in agonistic metabolites might be involved in the resistance to this drug. In fact, a novel active metabolite of tamoxifen has recently been identified (4-hydroxy- $N$-desmethyl-tamoxifen or endoxifen) in patients that received adjuvant tamoxifen (Stearns et al. 2003). Interestingly, the baseline levels of this metabolite were significantly higher in patients carrying the wild-type CYP2D6, a cytochrome P450 enzyme, as compared with women carrying a variant allele $(* 4,6,8)$. In patients with the wild-type allele the levels of endoxifen were significantly reduced by co-treatment with paroxetine, a selective serotonin reuptake inhibitor which is prescribed to alleviate tamoxifen-associated hot flashes and that can inhibit CYP enzymes. More recently, it has been shown that the recurrence-free survival of ER-positive breast cancer patients homozygous for the wild-type CYP2D6 allele was equal between tamoxifen-treated and tamoxifen-untreated patients (Wegman et al. 2005). In contrast, patients carrying at least one CYP2D6*4 allele showed a better outcome when treated with tamoxifen, as compared with nontreated patients. Taken together, these findings support a role for cytochrome $\mathrm{P} 450$ enzyme variants in regulating the response to tamoxifen.

\section{Co-regulators}

The transcriptional regulatory activity of ER is significantly influenced by the formation of multimolecular complexes that comprehends either coactivators or co-repressors. In this respect, a recent study demonstrated that high levels of expression of the co-activator AIB1 are associated with a shorter disease-free survival (DFS) in patients receiving tamoxifen as adjuvant treatment (Osborne et al. 2003). This outcome might also be due to important interactions between AIB1 and ErbB-2 that we will describe later. Interestingly, in untreated patients high levels of AIB1 were associated with a better outcome. These findings support laboratory studies suggesting that high levels of co-activators might enhance the agonistic effect of tamoxifen and therefore contribute to tamoxifen resistance.

Co-repressors are usually recruited by ER when an antagonist such as tamoxifen is bound to it (Lavinsky et al. 1998, McKenna et al. 1999). Although in vitro studies have suggested that reduced levels of corepressors might be associated with resistance to tamoxifen, no clinical data are available at this point that might sustain this hypothesis.

\section{Adaptation to estrogen withdrawal}

Pre-clinical and clinical findings strongly support the hypothesis that a major mechanism of resistance to endocrine therapy is the acquisition by breast cancer cells of an increased sensitivity to estrogen. As we will discuss later, the adaptation to estrogen withdrawal 
might be involved in the resistance to both tamoxifen and AIs. However, different molecular mechanisms have been hypothesized to cause this phenomenon.

Richard Santen's group have established an in vitro model of long-term estrogen deprivation (LTED) by culturing MCF-7 cells in estrogen-free medium to mimic the effects of ablative endocrine therapy (Santen et al. 2003). These cells adapted to grow in very low levels of estrogen that derive from plastic tissue culture dishes. The hypersensitivity of these cells was confirmed by the ability of estrogen to stimulate their proliferation at concentrations four-log lower as compared with wild-type MCF-7 cells (Masamura et al. 1995). In this model, Santen and co-workers found that the non-genomic ER $\alpha$ functions are significantly enhanced. In particular, LTED produced a 4- to 10-fold increase in the levels of ER $\alpha$ in MCF-7 cells, and the levels of ER $\alpha$ translocated at the plasma membrane are elevated. Growth factor signaling is significantly increased in LTED cells. Following estrogen treatment, ER $\alpha$ rapidly associates and phosphorylates Shc, an adaptor protein that is involved in tyrosine kinase receptor signaling. In this regard, association of ER $\alpha$, Shc and the IGF-1R has been demonstrated in LTED cells (Song et al. 2004). In addition, these cells show increased activation of both src and the ras/raf/MEK/MAPK signaling pathways that appear as key events in Ero-induced signaling in LTED cells (Song et al. 2002a,b). However, the demonstration that treatment of LTED cells with fulvestrant blocks MAPK activation, suggests that MAPK is a downstream effector of the ER $\alpha$-induced non-genomic signaling activated in these cells (Song et al. 2002a, Santen et al. 2003). Increased activation of the PI3K/AKT pathway has also been demonstrated in this model of LTED (Yue et al. 2003). In this respect, activation of both MAPK and AKT has been associated with resistance to endocrine therapy and a worse outcome in breast cancer patients (Gee et al. 2001, Perez-Tenorio et al. 2002). Additional studies from Santen's group did not exclude the possibility that an increase in basal levels of transcription of ER $\alpha$ regulated genes might have a role in adaptive hypersensitivity, although it does not represent the main mechanism involved in this phenomenon.

A different mechanism of resistance to LTED has been hypothesized by Mitch Dowsett's group (Johnston \& Dowsett 2003). In their model, LTED of MCF-7 cells initially produces a phase of estrogen hypersensitivity with cells showing increased levels of expression of $\mathrm{ER} \alpha$ and responding to concentrations of estrogen below $10^{-13} \mathrm{M}$ (Chan et al. 2002). In contrast with the findings of Santen, the model developed by Dowsett showed an enhanced transcriptional activity of ER $\alpha$ that is associated with an increase in the activation of growth factor pathways, which in turn trans-activate ER $\alpha$. Interestingly, after prolonged culture in the absence of estradiol $(80$ weeks), ER $\alpha$ appears to function independently from exogenous estradiol. This independent state has been hypothesized to be due to a supersensitivity of LTED to residual estrogen present in the medium (Chan et al. 2002, Martin et al. 2003). The estrogen-supersensitive breast cancer cells, defined as LTED-I, were maintained in insulin-containing medium, and the removal of insulin resulted in significant reduction of their growth and restoration of a hypersensitivity state. In this regard, the observations that LTED-I cells express elevated $E R \alpha$, that the transcriptional activity of EREs is significantly higher as compared with wildtype cells and that their growth is significantly inhibited by fulvestrant suggest that ER $\alpha$ has a key role in the insulin-dependent growth of these cells. Indeed, it has been shown that estrogen-supersensitive cells show increased levels of phosphorylation of $\mathrm{ER} \alpha$ at serine 118, a site that can be phosphorylated by different intracellular kinases. Dowsett's group has also demonstrated that supersensitive cells show an increased IGF-1R and ErbB-2 signaling, which is associated with increased MAPK activation (Martin et al. 2003). Blockade of either MAPK or EGFR/ ErbB-2 signaling produced significant reduction in both proliferation and ER $\alpha$ transcription in LTED-I. However, inhibition of either MEK/MAPK or PI3K/ AKT signaling did not block phosphorylation of ER $\alpha$ at serine 118, suggesting that additional kinases might be involved in this phenomenon. In conclusion, Dowsett's data suggest that different growth factor signaling pathways enhance ER $\alpha$ genomic activity in LTED-I cells.

More recently, an in vitro model of resistance to estrogen withdrawal (MCF-7X cells) has been developed by Nicholson and co-workers (Nicholson et al. 2004). Interestingly, these cells did not show any evidence of estrogen hypersensitivity. However, MCF-7X cells carried a functional ER $\alpha$, and their growth was inhibited by fulvestrant, implying that the $\mathrm{ER} \alpha$ pathway is still involved in the proliferation of these cells. The growth of MCF-7X cells was found to be mainly supported by the PI3K/AKT pathway (Nicholson et al. 2004). However, no activation of EGFR/ErbB-2 or IGF-1R signaling was demonstrated in these cells, suggesting that the phenomenon of adaptation to estrogen withdrawal might occur without increased sensitivity to estrogen or activation of classical growth factor receptors. 
We might speculate that estrogen-hypersensitive cells obtained following mid-term estrogen deprivation might represent a model of tamoxifen resistance, whereas LTED-I cells that have been obtained following longer estrogen deprivation and that show supersensitivity to residual estrogen are more likely to represent a model of resistance to AIs. Indeed, several findings suggest that the process of adaptive hypersensitivity obtained by estrogen withdrawal and the acquired resistance to tamoxifen resulting from longterm exposure to this drug share some common features. In fact, it has been demonstrated that following long-term exposure to tamoxifen ( $>5$ years) the growth of tamoxifen-resistant MCF-7 xenografts in nude mice is inhibited by estrogen (Yao et al. 2000). More recently, Richard Santen's group have confirmed that long-term exposure of MCF-7 xenografts to tamoxifen induces hypersensitivity to estrogen (Berstein et al. 2004). A common feature of tamoxifenresistant models in vivo is that their growth is stimulated by tamoxifen (Gottardis \& Jordan 1988, Osborne et al. 1991). In contrast, pure anti-estrogens such as fulvestrant inhibit the growth of these xenografts, thereby confirming that mechanisms of adaptation to tamoxifen include the enhanced agonistic effects of this drug (Gottardis et al. 1989, Osborne et al. 1994). As we will discuss below, the agonistic effect of tamoxifen in these resistant tumors is probably due to the enhanced growth factor signaling that is associated with acquired resistance to this drug (Schiff et al. 2003, 2004, Nicholson et al. 2004). In particular, both genomic and non-genomic activities of the tamoxifen-ER $\alpha$ complex are involved in this phenomenon. In fact, phosphorylation and activation of $E R \alpha$ by intracellular kinases leads to increased transcriptional activity of the receptor, increased production of estrogen-regulated growth factors such as TGF $\alpha$ and AR, and increased growth-factor-driven signaling; therefore reinforcing the above-described loop that will finally drive cell proliferation.

The phenomenon of acquired resistance to AIs has also recently been addressed by using MCF-7 cells stably transfected with human aromatase gene (MCF7Ca) (Long et al. 2004a, Brodie et al. 2005). MCF-7Ca tumors of mice treated with letrozole initially regressed but gradually resumed growth and had doubled in volume by week 21 of treatment (Brodie et al. 2005). Interestingly, it was found that letrozole-resistant tumors did not respond to either tamoxifen or fulvestrant as second-line therapy (Long et al. 2004a). These findings are in apparent contrast with the abovementioned reports from LTED in vitro experiments that suggested activity of fulvestrant in cells that had undergone adaptive supersensitivity, a condition that in vitro resembles resistance to AIs (Johnston \& Dowsett 2003). In this regard, previous reports from the same group showed that aromatase-overexpressing xenografts were sensitive to treatment with fulvestrant when tumors were transplanted in a different mouse and treatment with letrozole was suspended for a short period prior to treatment with fulvestrant (Long et al. 2002). In the subsequent report, letrozole-resistant tumors were immediately treated with fulvestrant. In addition, mice were switched off letrozole before treatment with fulvestrant (Long et al. 2004a, Brodie et al. 2005). In this respect, it has been shown that in LTED cells fulvestrant is effective in the presence of low concentrations of estrogen, whereas its efficacy is reduced if cells are treated with higher levels of estrogen. In agreement with these findings, treatment of MCF-7Ca xenografts with a combination of fulvestrant and letrozole resulted in tumor regression that was sustained for a significantly longer period as compared with fulvestrant or letrozole alone (Brodie et al. 2005). This observation supports the hypothesis that patients with resistance to AIs should receive fulvestrant in addition to these compounds, rather than fulvestrant alone. The Study of Faslodex, Exemestane and Arimidex (SoFEA) trial, will clinically address this question.

Preliminary data on the molecular characteristics of letrozole-resistant tumors are available. Although the levels of ER were decreased by $50 \%$ in letrozoleresistant tumors as compared with control tumors, $\mathrm{PgR}$ expression was modestly increased implying active ER signaling in these cells. Indeed, the levels of phosphorylation of ER $\alpha$ in serine 167 were significantly increased in letrozole-resistant tumors, suggesting ligand-independent activation of ER (Brodie et al. 2005). In addition, the levels of expression of ErbB-2 and the adaptor protein Grb-2, as well as the levels of phosphorylation of Shc and MAPK, were also increased in tumors growing on letrozole. Taken together, these preliminary findings suggest that acquired resistance to letrozole involves activation of growth factor signaling that might induce ligand-independent activation of ER $\alpha$. Interestingly, these phenomena are similar to those observed in MCF-7 cells following prolonged LTED and development of estrogen supersensitivity.

\section{Growth factor signaling in resistance to endocrine therapy}

The above-summarized data clearly demonstrate that growth factor signaling plays an important role in 
the adaptation of breast cancer cells to estrogen withdrawal. However, growth factor signaling is involved in both de novo and acquired resistance of breast cancer cells to endocrine manipulation through different mechanisms that we will discuss in this section.

The main mechanism of de novo resistance of breast cancer cells to endocrine therapy is loss of expression of ER. In this regard, the levels of expression of EGFR, ErbB-2 and TGF $\alpha$ are generally higher in ERnegative breast cancer as compared with ER-positive tumors (Normanno et al. 1994). Evidence suggests that activation of growth factor signaling might indeed reduce ER $\alpha$ expression and/or function. For example, treatment with EGF, IGF-I, TGF $\beta$ or phorbol myristate acetate (TPA) reduces the levels of ER $\alpha$ mRNA and protein in MCF-7 cells (Martin et al. 1995, Stoica et al. 1997, 2000a,b). Increased signaling through EGFR, PI3K/AKT, PKA and PKC is involved in this phenomenon. Furthermore, heregulin, which can activate both EGFR and ErbB-2 through formation of heterodimers with either ErbB-3 or ErbB-4, has been shown to depress ER $\alpha$ or its transcriptional activity (Mueller et al. 1995, Tang et al. 1996). Analogously, transfection of constitutively active ErbB-2, Raf1 or MEK resulted in significant reduction in the expression of ER $\alpha$ mRNA and protein, and in marked suppression in the transcription of estrogenregulated genes, events leading to the development of an estrogen-independent phenotype (Liu et al. 1995, Pietras et al. 1995, El-Ashry et al. 1997, Oh et al. 2001). Taken together, these data suggest that growth factor signaling might contribute to transcriptional repression of ER $\alpha$ expression in breast cancer cells, thus resulting in resistance to endocrine treatment.

The involvement of ErbB-2 in de novo resistance of breast cancer cells to tamoxifen has long been hypothesized (Benz et al. 1993, Pietras et al. 1995). More recently, Shou et al. (2004) demonstrated that in the presence of low levels of estrogen tamoxifen acts as an agonist for MCF-7/HER2-18 cells. In these cells, tamoxifen as well as estrogen induces activation of EGFR/ErbB-2 signaling, which leads to activation of both MAPK and AKT signal transduction pathways. These intracellular kinases phosphorylate and functionally activate both $\mathrm{ER} \alpha$ and the co-activator AIB1. Furthermore, in MCF-7/HER2-18 cells treatment with tamoxifen increased the expression of estrogen-regulated genes, nearly as well as estrogen itself. This phenomenon is due to the ability of the tamoxifen-ER $\alpha$ complex to recruit co-activators such as AIB1 rather than co-repressors in ErbB-2-overexpressing cells. Interestingly, all these phenomena could be blocked by treatment with the EGFRtyrosine kinase inhibitor gefitinib, suggesting that EGFR/ErbB-2 signaling is directly involved in the growth-promoting activity of tamoxifen in ErbB-2overexpressing cells. In this respect, gefitinib was highly effective in inhibiting the tamoxifen-induced growth of MCF-7/HER2-18 cells, whereas it had little effect on estrogen-induced growth. The abovementioned findings are in agreement with clinical observations indicating that tumors that co-express ErbB-2 and AIB1 have a poor outcome when treated with tamoxifen (Osborne et al. 2003). Furthermore, preliminary studies have shown that patients that express either ErbB-2 or EGFR are relatively resistant to tamoxifen, whereas they are sensitive to AIs (Dowsett et al. 2001, Ellis et al. 2001).

Experimental evidence provided by Robert Nicholson's group has demonstrated that EGFR/ ErbB-2 signaling is involved in the acquired tamoxifen resistance of breast cancer cells (Nicholson et al. 2004). This group has established an in vitro tamoxifenresistant model derived from MCF-7 cells. These cells showed increased levels of expression of EGFR and ErbB-2, increased activation of EGFR/ErbB-2 heterodimers and increased phosphorylation of MAPK, $\mathrm{AKT}$ and nuclear ER $\alpha$ in serine residues 118 and 167 (Britton et al. 2003, Hutcheson et al. 2003, Knowlden et al. 2003a, Jordan et al. 2004). The growth of these cells was significantly inhibited by treatment with either gefitinib or trastuzumab (Gee et al. 2003). Interestingly, phosphorylation of $E R \alpha$ and $E R \alpha-$ induced transcription was increased by exogenous EGF-like peptides and was blocked by treatment with gefitinib. The enhanced transcriptional activity of ER $\alpha$ produced an increased synthesis of TGF $\alpha$ and AR that sustains the EGFR/ErbB-2 autocrine loop operating in tamoxifen-resistant cells (Hutcheson et al. 2003). An involvement of IGF-1R signaling in tamoxifen-resistant cells has also been shown. In fact, it has recently been reported that IGF-II induces an increase of both IGF-1R and EGFR activation in tamoxifen-resistant cells (Knowlden et al. 2003b, Hutcheson et al. 2004). Taken together, these findings suggest that enhanced growth factor signaling, which induces both genomic and non-genomic activities of $E R$, is the main mechanism of acquired resistance to tamoxifen. Notably, these molecular mechanisms are similar to those observed in estrogen-hypersensitive cells. Interestingly, MCF-7 cells adapted to grow in fulvestrant showed an increased EGFR signaling, suggesting that growth factor signaling also plays a central role in the resistance to this novel compound (McClelland et al. 2001). In agreement with these 
in vitro findings, increased levels of expression of ErbB-2 and increased activation of p38-MAPK have been described in patients with acquired resistance to tamoxifen (Gutierrez et al. 2005). Interestingly, activation of p38-MAPK was observed in MCF-7 xenografts treated with estrogen deprivation plus tamoxifen, but not with estrogen deprivation alone, suggesting that p38-MAPK activation is a peculiar phenomenon of resistance to tamoxifen. In addition, preliminary results of a phase-II clinical trial of gefitinib in tamoxifen-resistant advanced breast cancer patients suggest clinical activity of anti-EGFR agents in this subset of patients (Robertson et al. 2003a). However, larger clinical trials are needed to confirm these preliminary findings.

Activation of growth factor signaling might also lead to the development of an estrogen-independent phenotype as an ultimate escape mechanism from the anti-tumor activity of anti-estrogen drugs. In this respect, the development of an estrogen-independent phenotype appears to be a complex phenomenon. For example, overexpression of TGF $\alpha$, EGFR or, more recently, the EGF-CFC protein CRIPTO- 1 in estrogenresponsive breast cancer cells was not able to induce an estrogen-independent phenotype (Clarke et al. 1989, Valverius et al. 1990, Normanno et al. 2004a). In contrast, overexpression of ErbB-2 or of heregulin, which can induce ErbB-2 transactivation by binding to ErbB-3 and ErbB-4, resulted in estrogen-independent growth and resistance to anti-estrogen (Liu et al. 1995, Pietras et al. 1995, Tang et al. 1996, Atlas et al. 2003). In addition, constitutive activation of signaling molecules downstream of tyrosine kinase receptors such as MEK or raf-1 also resulted in estrogen independence and resistance to anti-estrogens, as above described (El-Ashry et al. 1997, Oh et al. 2001). The reduced ability of EGFR to induce suppression of $\mathrm{ER} \alpha$ expression and estrogen independence as compared with ErbB-2 could be due to the low levels of activation of EGFR in the absence of exogenous ligands (Oh et al. 2001). Taken together, these data suggest that prolonged and sustained activation of growth factor signaling pathways might finally lead to the development of an estrogen-independent phenotype. Suppression of ER $\alpha$ expression through the mechanisms that we have above described might have a role in this phenomenon. In this regard, Nicholson et al. (2004) have recently reported that fulvestrantresistant cells lost expression of $\mathrm{ER} \alpha$ following prolonged exposure to anti-estrogen. Expression of $\mathrm{ER} \alpha$ did not resume in fulvestrant-resistant cells following removal of the drug, and it was associated with the development of an estrogen-independent phenotype. Interestingly, these authors reported that fulvestrant-resistant cells were more prone to develop an ER-negative phenotype as compared with tamoxifen-resistant cells or cells that were long-term cultured in the absence of estrogen. These observations suggest that the development of a specific phenotype might depend on the type of endocrine agent that is employed.

\section{Trying to summarize the mechanisms of resistance to endocrine manipulation: the action-reaction hypothesis}

As described in the above paragraphs, several different mechanisms are involved in the resistance of breast cancer cells to endocrine manipulation. Such mechanisms can lead breast cancer cells from an estrogendependent phenotype - which responds to endocrine manipulation - to a non-responder phenotype, and eventually to an estrogen-independent phenotype. However, such phenotypic modifications are not spontaneous but are induced in breast cancer cells by the selective pressure of hormonal agents. In fact, compelling evidence suggests that for each 'action' carried out with the aim of blocking estrogen stimulation of breast cancer cells (i.e. treatment with anti-estrogen), there are one or more corresponding 'reactions' that tumor cells can use to escape our attempts to block their growth: estrogen hypersensitivity associated with increased transcriptional activity of $E R \alpha$ and/or increased non-genomic activity of $E R \alpha$; estrogen supersensitivity; increased growth factor signaling; suppression of ER $\alpha$ expression; and finally estrogen independence. Although the 'paths' that tumor cells can follow to escape hormonal treatment are various and may depend on different factors, what we may hypothesize is that this action-reaction rule leads to a step-wise increase in the ability of breast cancer cells to escape endocrine manipulation (Fig. 2). Indeed, untreated ER-positive breast carcinomas are likely to be sensitive to treatment with any hormonal agent, i.e. tamoxifen, AIs and fulvestrant. The majority of breast cancer patients have been treated up to now with tamoxifen. Breast cancer cells that acquire resistance to tamoxifen show phenotypic characteristics that are similar to the initial adaptive hypersensitivity described by Santen et al. (2003) and Dowsett (2003). In these cells growth factor signaling is increased and tamoxifen might behave as an agonist. Pre-clinical and clinical observations suggest that the growth of tamoxifen-resistant tumors can be blocked by either AIs, which produce a more pronounced and prolonged estrogen deprivation, or by fulvestrant that 


\section{ESTROGEN INDEPENDENT PHENOTYPE}

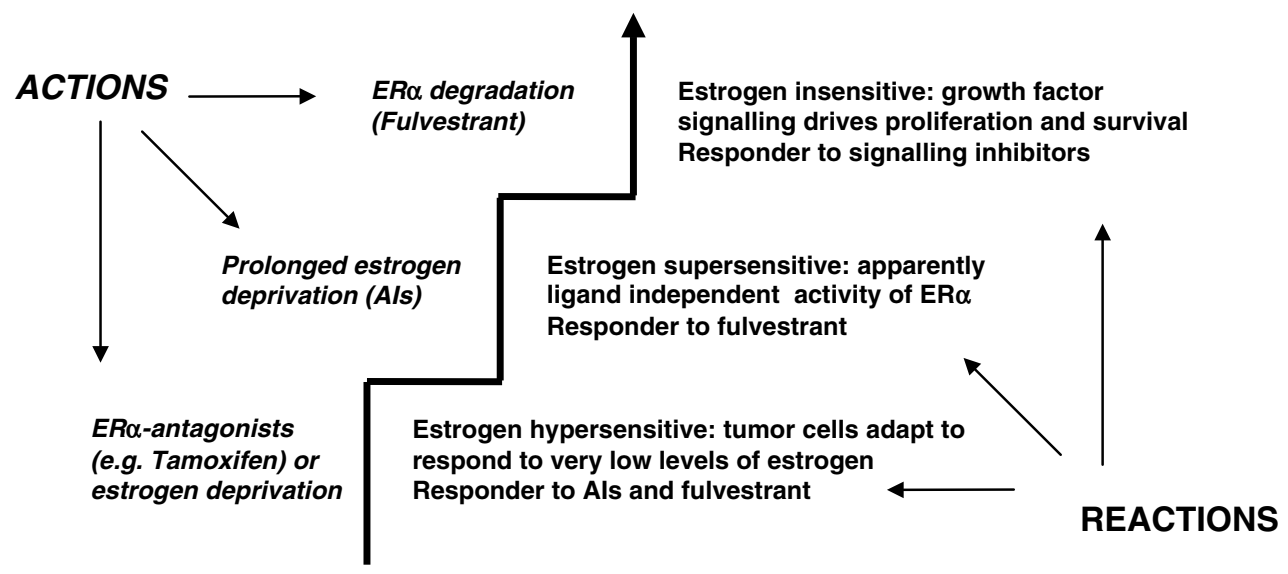

ESTROGEN DEPENDENT PHENOTYPE

Figure 2 The action-reaction hypothesis: at each 'action' aiming to block estrogen stimulation of breast cancer cells (i.e. treatment with anti-estrogen), there are one or more corresponding 'reactions' that tumor cells can use to escape our attempts to block their growth. Als, aromatase inhibitors.

destabilizes ER $\alpha$. However, deprivation of estrogen for a longer period leads to the development of an estrogen-supersensitive phenotype; this phenotype has been described by Dowsett's group and is likely to represent a model of resistance to AIs. In these cells, activation of both EGFR/ErbB-2 and IGF-1R signaling occurs. However, estrogen-supersensitive cells are still growth inhibited by treatment with fulvestrant, demonstrating a role of ER $\alpha$ in the growth of these cells. In this regard, findings from Nicholson's group suggest that long-term exposure to fulvestrant might lead to loss of expression of ER $\alpha$ and development of an estrogen-independent phenotype in breast cancer cells. In any case, the development of an estrogenindependent phenotype is the ultimate mechanism of resistance to hormonal therapy, and it most probably occurs independently from the type of hormonal agent following long-term treatment. In fact, activation of different growth factor-driven signaling pathways accompanies each step of the development of resistance to endocrine manipulation. Growth factor signaling down-regulates both $\mathrm{ER} \alpha$ and $\mathrm{PgR}$ transcription, and can substitute for estrogen in supporting the growth and the survival of breast cancer cells.

Of course, breast cancer cells might follow different 'paths' in developing a resistant or an estrogenindependent phenotype, depending on the type of hormonal agent, on the genetic background and other, as yet undefined, factors. For example, the observation that only a subset of tamoxifen-resistant patients respond to treatment with AIs implies that some of the tumors progressing on tamoxifen therapy may have acquired some degree of estrogen-independent growth. It is also important to note that this model has been hypothesized by using information deriving mainly from in vitro studies. In this respect, the pharmacokinetics of in vitro studies is 'simplified' since tumor cells are directly exposed to pharmacologically active concentrations of drugs. Furthermore, other variables such as the metabolism of drugs are not taken into account in such models. Of course, experiments in animals are more informative. However, the pharmacokinetics and the pharmacodynamics of many drugs in mice are not superimposable to humans.

Finally, our model is consistent with the observation that agents that are active in advanced disease and in resistant tumors might not be as active in first-line therapy since they function by blocking mechanisms that develop during acquisition of resistance. For example, fulvestrant is able to block the growth of both estrogen-hypersensitive and -supersensitive cells. In clinical trials fulvestrant is not more effective than tamoxifen as a first-line therapy, whereas it is as effective as AIs as a second-line treatment of advanced breast cancer and it is also active in AI-resistant patients, as we will discuss below. In this respect, it has been hypothesized that tamoxifen might be more effective than fulvestrant in first-line therapy because the tamoxifen-ER complex might compete with other transcription factors in binding to estrogen-regulated genes, therefore blocking their function (McDonnell 
2005). This phenomenon does not occur for fulvestrant or similar compounds that destabilize ER. However, in advanced disease the agonist effects of tamoxifen increase; and in this setting fulvestrant, which has no agonistic effects, is more effective. An additional example derives from clinical and pre-clinical experiences with EGFR-tyrosine kinase inhibitors such as gefitinib. The results of clinical trials of gefitinib in breast cancer are disappointing, with a disease control rate of approximately 10\% (Normanno et al. 2004b). In contrast, preliminary results of a phase-II trial of gefitinib in tamoxifen-resistant patients suggest a much higher disease control rate in this specific subset of patients (Robertson et al. 2003a). We have described the mechanisms involved in this phenomenon above. This is a clear example of selection of EGFRdependent cells following treatment with tamoxifen. However, EGFR signaling might contribute to tumor growth and resistance to endocrine therapy in untreated patients as well. In this regard, the results of a randomized phase-II trial of gefitinib plus placebo versus gefitinib plus anastrozole as neoadjuvant therapy in ER-positive and EGFR-positive breast cancer patients have recently been published (Polychronis et al. 2005). Expression of EGFR occurs in approximately $30 \%$ of ER-positive patients, and it has been reported to be associated with resistance to tamoxifen (Salomon et al. 1995, Dowsett et al. 2001, Ellis et al. 2001). In this specific subset of patients, gefitinib was able to reduce by $92.4 \%$ the Ki67 labeling index and to induce partial responses in 14/28 patients. This phenomenon was also associated with a significant reduction in the levels of phosphorylation of ER at serine 118. The combination of anastrozole plus gefitinib produced a greater reduction in Ki67 labeling index as compared with gefitinib alone, and partial remissions in approximately $55 \%$ of the patients. These results clearly demonstrate that blockade of EGFR in ER-positive tumors that express this receptor might lead to significant reduction of tumor growth.

As we will describe in next paragraphs, our hypothesis is largely confirmed by the results of clinical trials in breast cancer patients. More importantly, this evidence is the basis for novel therapeutic approaches for breast carcinoma with combinations of antihormones and signal transduction inhibitors.

\section{Clinical trials with novel anti-estrogen drugs}

In the next paragraphs, data coming from recent clinical trials of hormonal treatment of breast cancer, both in the metastatic and adjuvant settings, are summarized. In both settings, the major changes are due to the availability of third-generation AIs that have been brought into large phase-III trials for use as adjuvant treatment following the promising results reported in metastatic disease. In addition, in the metastatic setting, fulvestrant - the only SERD available for treatment of patients - is being studied to establish its optimal position in the strategy of hormonal treatments.

\section{Metastatic disease}

There are three third-generation AIs available for clinical use: the non-steroidal anastrozole and letrozole, and the steroidal AI exemestane. These drugs have been registered for treatment of advanced breast cancer following the results of randomized phase-III clinical trials. These trials can be broadly divided into two sets. The first set includes trials of second-line therapy, dedicated to patients who progressed after tamoxifen treatment (Buzdar et al. 1998, 2001, Dombernowsky et al. 1998, Kaufmann et al. 2000). In these trials, AIs were compared with megestrol acetate; outcomes were never worse for AIs and in some cases (overall survival (OS) with anastrozole, time to progression with exemestane, response rate with letrozole) were significantly improved. More importantly, third-generation AIs showed advantages in comparison with tamoxifen in first-line treatment clinical trials. Anastrozole, indeed, was compared with tamoxifen in two trials (Bonneterre et al. 2000, Nabholtz et al. 2000); while in one of these there was no difference between anastrozole and tamoxifen for all study end-points, in the other anastrozole significantly prolonged time to progression. Letrozole produced higher response rate and longer time to progression than tamoxifen in the largest trial of this group, including more than 900 patients (Mouridsen et al. 2003). Finally, exemestane resulted in higher response rate and longer time to progression in a randomized phase-III trial of the European Organization for Research and Treatment of Cancer (EORTC; Paridaens et al. 2004). Overall, AIs were slightly more effective than tamoxifen in metastatic breast cancer; however, the wide use of tamoxifen in an adjuvant setting has rendered AIs the most useful drugs for the treatment of this stage of disease.

A much lower number of trials have been performed for the clinical development of fulvestrant. In a small phase-II trial, the drug had shown activity with an objective response in 7 out of 19 patients (37\%) with advanced breast cancer, resistant to tamoxifen (Howell 
et al. 1996). Following this result, the efficacy of fulvestrant has been compared with anastrozole in two randomized phase-III trials, dedicated to postmenopausal women with advanced breast cancer which had progressed after prior endocrine therapy (Howell et al. 2002, Osborne et al. 2002). The results of these trials demonstrate that fulvestrant is well tolerated and is at least as effective as anastrozole. A prospectively planned, combined analysis of data from those two clinical trials showed that median time to progression was 5.5 months and 4.1 months, and overall response rates were 19.2 and $16.5 \%$ for fulvestrant and anastrozole respectively (Robertson et al. 2003b). Based on these results, fulvestrant has recently been approved by the US Food and Drug Administration and the European Agency for the Evaluation of Medicinal Products (EMEA) for the treatment of hormone-receptor-positive, metastatic breast cancer in postmenopausal women progressing on prior anti-estrogen therapy. However, noninferiority of fulvestrant could not be demonstrated in a randomized trial versus tamoxifen with 587 patients at their first-line hormonal treatment for metastatic breast cancer (Howell et al. 2004). Median time to progression was 6.8 and 8.3 months for fulvestrant and tamoxifen respectively, and objective response rates were 31.6 and $33.9 \%$ respectively.

Based on the consideration that treatment of metastatic disease is palliative and that for patients with ER-positive tumors it is reasonable to exploit the potential activity of all available endocrine treatments, the choice of the optimal sequence is of clinical relevance (Piccart et al. 2003, Gradishar 2004). This choice is, of course, affected by which treatment has been given in the adjuvant setting. Currently, because most metastatic patients with ER-positive tumors have received adjuvant tamoxifen and the use of fulvestrant is not yet widespread, the choice is practically limited to AIs, with some attempts at sequencing a nonsteroidal AI (anastrozole or letrozole) and the steroidal exemestane, particularly in cases of patients who respond to the first line. The introduction of fulvestrant is actually opening new scenarios. The two above-reported clinical trials comparing fulvestrant with anastrozole support the hypothesis that its efficacy is comparable with that of anastrozole in the treatment of patients resistant to tamoxifen. In support of its use before AIs there are also data showing that AIs still retain some activity after progression on second-line fulvestrant (Cheung et al. 2002, Vergote et al. 2003). However, it should be emphasized that such activity is quite low with a lower than $10 \%$ rate of partial responses and about $40 \%$ rate of clinical benefit, including stable disease lasting more than 24 weeks. This observation is apparently in contrast with pre-clinical findings suggesting that resistance to fulvestrant is associated with activation of EGFR/ErbB-2 signaling and estrogen independence (McClelland et al. 2001, Nicholson et al. 2004). However, it is conceivable that at suspension of treatment with fulvestrant, some patients might return to a hypersensitive state in which AIs are active. Furthermore, resistance to fulvestrant might be due to different mechanisms that might alter the intratumoral concentration of the drug or its activity. For example, it has been recently demonstrated that an intact NEDD8 pathway that leads to ER $\alpha$ ubiquitination and degradation is essential for the antiproliferative activity of fulvestrant (Fan et al. 2003). Therefore, in the latter hypothesis, tumor cells might become resistant to fulvestrant and be still sensitive to anti-estrogen therapy with AIs. Finally, more recent clinical data support the hypothesis that AI-resistant tumors might be still sensitive to fulvestrant with a clinical benefit rate of about 30\% (Ingle et al. 2004, Perey et al. 2004). In conclusion, although some interesting indications have been reported, convincing randomized clinical trials addressing the relative efficacy of different sequences of hormonal treatment in metastatic breast cancer are lacking.

\section{Adjuvant treatment}

Following the encouraging results of trials in metastatic disease, the three third-generation AIs have been pushed into phase-III trials of adjuvant treatment. The results of some of these trials are already available, whereas some studies are still ongoing. Based on results of the Oxford Overview (Early Breast Cancer Trialist Group 1998), all trials include tamoxifen given for 5 years as standard treatment and comparator (Fig. 3). Owing to the significant but relatively small advantage observed in clinical trials conducted in patients with metastatic disease, all adjuvant trials are planned to detect small advantages; thus, also in consideration of the relatively low rate of events expected for early breast cancer patients with ERpositive tumors, all the studies have planned to enroll an extremely high number of patients. Thanks to the large sample size, the number of events required for $a$ priori planned analyses (either definitive or ad interim) might be reached in quite a short time following the end of enrolment. Thus, although none of these trials can be criticized for the statistical methodology that was applied, there is room to consider that clinical maturity of data could not have always been reached 
Up-front strategy (ATAC, BIG 1-98)

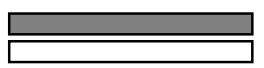

Early-switch strategy (IES, ARNO, ITA)

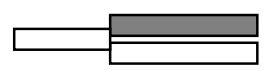

Late-switch strategy (MA.17)

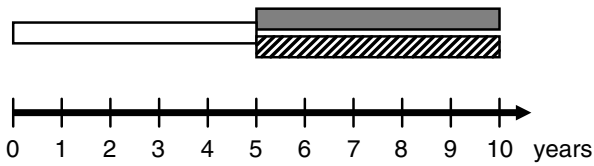

Figure 3 Different strategies employed in clinical trials of Als in early breast cancer.

at the moment of releasing analysis results. This consideration, of course, becomes important in the presence of statistically significant results that can, in principle, change the patterns of clinical practice.

All the trials that have been reported as of February 2005 have produced positive results for AIs, with the exception of the trials using anastrozole + tamoxifen combined treatment; the results for this treatment were not better than tamoxifen alone in the Arimidex or Tamoxifen Alone or in Combination (ATAC) trial (Baum et al. 2002). In this trial, anastrozole given alone for 5 years was more effective than tamoxifen; at the most recent update (Howell et al. 2005), after a median follow-up of 68 months (limiting the analysis to 5216 patients with positive hormone receptors), the absolute advantage in DFS for those receiving anastrozole is $2.8 \%$ at 5 years, with an overall hazard ratio of 0.83 (95\% confidence interval (CI), 0.73-0.94; $P=0.005)$. Interestingly, the size of absolute DFS gain in this study is progressively increasing, going from $1.7 \%$ to $2.4,2.8$ and $3.7 \%$ in the third, fourth, fifth and sixth year of follow-up respectively. If such a trend is confirmed after longer observation, this phenomenon will be similar to that observed in clinical trials of tamoxifen versus no treatment, where the reduction of the annual odds of recurrence is maintained over a period of time extending about 5 years after the end of active treatment. No effect of anastrozole has yet been seen on OS in the ATAC trial; however, it should be noted that $40 \%$ of deaths (331 out of 831 ) reported in the study were due to causes other than cancer, as a consequence of the patients' age.

A comparison similar to that of the ATAC trial has recently been reported with letrozole, at the 2005
St Gallen Breast Cancer Consensus Conference (BIG 1-98 Collaborative Group 2005). In the Breast International Group (BIG) 1-98 trial four arms are planned: the standard treament (tamoxifen for 5 years); and three experimental treatments, namely letrozole for 5 years, tamoxifen for 2 years followed by letrozole for 3 years, and letrozole for 2 years followed by tamoxifen for 3 years. Data have been presented for the head-to-head comparison of tamoxifen versus letrozole, summing up patients in the single-drug arms and those in the sequential arms, the latter being censored at the date of drug switch. The a priori planned primary core analysis, done with 779 events out of 8010 patients and a median follow-up of 26 months, has shown an absolute $2.6 \%$ improvement in DFS at 5 years, corresponding to a hazard ratio of 0.81 (95\% CI, $0.70-0.93 ; P=0.003)$. As in the ATAC trial, the absolute difference increases during years of follow-up, going from $1.5 \%$ at 3 years to 2.2 and $2.6 \%$ at 4 and 5 years. As far as OS is concerned, the rate of deaths is probably still too low $(4.1 \%$ with letrozole and $4.8 \%$ with tamoxifen, $P=0.18)$ to observe significant effects.

Exemestane has been studied within the Intergroup Exemestane Study (IES) that was designed to test whether switching to exemestane, after 2-3 years of tamoxifen therapy, was more effective than continuing tamoxifen therapy for the remainder of the 5 years of treatment (Coombes et al. 2004). The study included 4742 patients and data were released after the second interim analysis following the recommendation of the Independent Data and Safety Monitoring Committee. With a median follow-up of 31 months and 449 events (recurrence, contralateral breast cancer or death without cancer), there is an absolute advantage in DFS at 3 years after randomization (approximately 5 years after surgery) of $4.7 \%$, with an adjusted hazard ratio of 0.67 (95\% CI, 0.56-0.82; $P<0.001$ ). No significant effect has been observed yet for OS (hazard ratio 0.89 ; 95\% CI, $0.67-1.13 ; P=0.41$ ), as for the abovereported trials. Similar results have been reported in two trials with anastrozole that employed a 'switch' approach. In the Italian Tamoxifen Arimidex (ITA) trial, a study with 448 patients enrolled, a $0.35(95 \%$ CI, 0.21-0.63) hazard ratio of recurrence was found favoring the sequential treatment with tamoxifen followed by anastrozole as compared with tamoxifen alone (Boccardo et al. 2003). In the combined ABCSG8/ARNO95 trial with 3224 patients, a hazard ratio of recurrence of $0.60 \quad(95 \% \mathrm{CI}, 0.44-0.81$; $P=0.0009$ ) favoring anastrozole following 2 years of tamoxifen versus tamoxifen has recently been reported (Jakesz et al. 2004). 
A truly innovative strategy, the so-called 'extended adjuvant treatment' has been tested in the MA.17 trial in which patients who completed 5 years of adjuvant tamoxifen were randomized to receive letrozole or placebo for 5 additional years (Goss et al. 2003). This strategy differs from prolongation of adjuvant tamoxifen beyond the fifth year, which has produced negative results and is no longer considered as a treatment option in clinical practice, although the results of some large clinical trials are still awaited. Data from the MA.17 trial were released after the first interim analysis, with 5187 patients enrolled, a median follow-up of 2.4 years and 207 events for DFS analysis. According to protocol plans, a great benefit in DFS, for patients receiving letrozole as compared with those receiving placebo, was the reason for early disclosure of blinding. At 4 years of follow-up (thus at about 9 years from surgery) letrozole produced a $6 \%$ difference in DFS (Goss et al. 2003); this was slightly reduced to $4.8 \%$ in a subsequent updated analysis with 247 events (Goss et al. 2004). As far as OS is considered, no significant difference has been seen to date in the whole study group. Following its early closure, the MA.17 study is continuing offering to patients who reach the end of 5 years of letrozole (10 years of adjuvant treatment overall) the option of being randomized to a further 5 years of letrozole or placebo.

All the above adjuvant trials have been reported with subgroup analyses, planned or unplanned, that might be of interest to generate hypotheses for future studies. Such hypotheses, if verified, could help inform the selection of the optimal patients for AI adjuvant treatment and the choice among different available inhibitors. In both the ATAC and ABCSG8/ARNO95 trials (Dowsett 2003, Jakesz et al. 2004) the advantage of anastrozole over tamoxifen seems larger in the subgroup of patients with tumors that express ER but not PgR. In the IES study with exemestane (Coombes et al. 2004), and in the MA.17 (Goss et al. 2004) and BIG 1-98 (BIG 1-98 Collaborative Group 2005) studies, both with letrozole, such a trend is not evident. Another interesting suggestion is that the effect of AIs may be different according to whether patients had or had not received adjuvant chemotherapy before starting adjuvant treatment. Indeed, the effect of anastrozole seems similar to tamoxifen in the ATAC study among patients who had previously received adjuvant chemotherapy. However, it is reasonable that the small number of ER-negative patients who were enrolled in the ATAC trial could represent about onethird of the patients in the subgroup who received adjuvant chemotherapy, and this phenomenon might dilute the effect of anastrozole as compared with tamoxifen, because both drugs are ineffective against ER-negative tumors. In contrast, in the BIG 1-98 trial, the letrozole effect is even more evident (hazard ratio 0.70 versus 0.85 ) among patients who had received previous adjuvant chemotherapy. In the IES study, the effect of exemestane appears completely independent of previous chemotherapy. However, it must be considered that adjuvant chemotherapy is usually given to ER-positive patients only in the presence of other negative prognostic factors; therefore, such analyses should always be multivariate to understand whether the considered factor has a predictive value per se or just because it is correlated with other risk factors.

Due to the relatively good prognosis of ER-positive breast cancer patients and the long duration of adjuvant endocrine treatment, an important issue to consider is the toxicity of AIs. Typically, side effects can be divided in two groups: those appearing during treatment and those that could also potentially be expected after treatment cessation, with a variable time lag. To date we have little information on the latter group of side effects because the median followup time of all published trials is still quite short (ranging from 2.5 to 5 years); however, the picture for short- or medium-term side effects is substantially clearer. Gynecological side effects (including vaginal bleeding and discharge) are usually reduced with AIs as compared with tamoxifen; in the ATAC trial, the one with longest follow-up, there was also a significant reduction of the incidence of endometrial cancer, a feared - although rare - side effect of tamoxifen. Reduced levels of estrogens induced by AIs have detrimental effects on bone, as demonstrated by an increase in arthralgia, osteoporosis and clinical fractures in all the studies with the exception of the MA.17 trial, where letrozole is compared with placebo and not with tamoxifen. This supports the hypothesis that the detrimental effects of AIs on bone are particularly evident when they are compared with tamoxifen because the latter has positive effects on bone thanks to its site-specific estrogen-agonistic mechanism of action. Another important issue is that of cardiovascular side effects. Overall, thromboembolic vascular side effects are reduced with AIs. However, all three studies comparing AI with tamoxifen report a higher, although not significant, rate of cardiac events. For example, in the BIG 1-98 study 20 deaths due to stroke or cardiac events have been reported with letrozole as compared with 7 in the tamoxifen arm (Thurlimann et al. 2005). Of course, it must be underlined that the follow-up in adjuvant trials is still too short to derive 
definitive conclusions, and that cross-trial comparisons of different AIs is not correct and should not be done.

A quality of life analysis has been performed in a subgroup of patients participating in the ATAC study (Fallowfield et al. 2004); while global scores of the applied measures did not vary significantly between the anastrozole and tamoxifen arms, the pattern of patient-reported side effects showed significant differences. For example, while vaginal discharge, irritation and bleeding are reduced with anastrozole, vaginal dryness is significantly worsened - together with pain or discomfort with intercourse; in addition, a significant loss of interest in sex is reported. Further quality of life analyses are required and consideration of such effects should constitute part of the information to be given to patients who are faced with a treatment choice of an endocrine adjuvant treatment for breast cancer.

In conclusion, thanks to the large clinical trials reported to date, it is clear that the addition of AIs in various forms - to the adjuvant treatment of breast cancer does improve patients' outcomes. However, there are still open questions that need to be addressed in order to choose the best strategy of treatment. First, we do not know whether different AIs vary in their efficacy and safety because there are no head-to-head comparisons in the adjuvant setting, and data are also scanty in the metastatic setting. Secondly, different strategies have been used (AI upfront, early and late switch from tamoxifen to AI) but the results of direct comparisons are not available yet. Thirdly, subgroup analyses have produced discordant results that cannot be explained because of the lack of direct comparisons among AIs. Finally, important questions, such as possible interactions with ErbB-2, have not been addressed at all.

\section{Hormonal treatment in ErbB-2-positive breast cancer patients}

Conflicting results have been reported up to now on the role of ErbB-2 in regulating the sensitivity of ER-positive breast cancer patients to tamoxifen and, more generally, to endocrine therapy. However, it should be considered that variability of many key aspects (such as the technique used for ErbB-2 evaluation or the baseline characteristics of patients) render indirect comparisons among studies extremely difficult. In addition, the proportion of ER-positive patients among the ErbB-2-positive patients is approximately $10 \%$. As reported by Knoop et al. (2001), in order to find a significant hazard ratio of 1.4 for the interaction between administration of tamoxifen and ErbB-2 expression in ER-positive patients, approximately 2000 events would be required in a study comparing tamoxifen with no treatment. None of the studies summarized below had that power and such a trial will never be performed because a comparison of tamoxifen versus no treatment, in patients with ER-positive tumors, would be now considered unethical.

The first evidence of a potential negative correlation between expression of ErbB-2 and response to tamoxifen came from the Gruppo Universitario Napoletano (GUN)-1 study which evaluated ErbB-2 over-expression in 145 out of 308 node-negative breast cancer patients, randomly assigned to receive 2 years of tamoxifen $(n=59)$ or no adjuvant treatment $(n=86)$. Adjuvant tamoxifen was associated with an improved DFS and OS in ErbB-2-negative patients, but with a worse DFS and OS in patients with ErbB-2-positive tumors (Carlomagno et al. 1996, De Placido et al. 2003). In agreement with these findings, Stal et al. (2000) found that ErbB-2-positive patients did not receive further benefit from 5 years of tamoxifen compared with 2 years of treatment, whereas prolonged treatment produced significant benefit in ErbB-2-negative patients. However, other studies came to different conclusions. Berry et al. (2000) examined the interaction between ErbB-2 expression and tamoxifen effectiveness in patients with ER-positive, node-positive disease treated with adjuvant cyclophosphamide, doxorubicin and fluorouracil (Cancer and Leukemia Group B 8541). In this protocol, tamoxifen assignment was not randomized, but was at the physician's discretion. Approximately half of the 651 ErbB-2-positive patients received tamoxifen. The reduction in risk of disease recurrence or death resulting from tamoxifen was similar in negative or positive ErbB-2 patients, and the interaction between tamoxifen and ErbB-2 status was not significant in multivariate analysis. However, all patients in this study received chemotherapy, and this could have masked the impaired efficacy of hormonal treatment. In the Danish Breast Cancer Cooperative Group's 77c protocol (Knoop et al. 2001), 1716 postmenopausal patients with a high risk of recurrence were randomly assigned to tamoxifen (868 women) or to observation (848 women). Multivariate analysis demonstrated no increased risk of recurrence after treatment with tamoxifen for ErbB-2-positive patients. However, in this study tamoxifen was given for only 1 year, which has now been proven to be inferior to 2-year and 5-year treatment. Furthermore, ErbB-2positive patients were combined with those positive for EGFR and, despite this combining, the number of 
ErbB-2- or EGFR-positive patients receiving tamoxifen was only 51 .

Several retrospective analysis of studies with tamoxifen in advanced breast cancer have shown a worse outcome for patients expressing high levels of ErbB-2 as compared with ErbB-2-negative patients, although this evidence was not confirmed in all studies (Wright et al. 1992, Elledge et al. 1998, Houston et al. 1999, Arpino et al. 2004). However, this phenomenon confirms a worse prognosis for ErbB-2-expressing patients treated with tamoxifen, rather than a predictive role of ErbB-2 in the response to this drug.

The availability of novel anti-estrogenic drugs such as AIs has instigated investigations into the efficacy of these drugs compared with tamoxifen in patients with overexpression of ErbB-2. A study from Lipton et al. (2003) suggested that letrozole is superior to tamoxifen as first-line treatment, independent of serum ErbB-2 levels. Furthermore, Ellis et al. (2001), in a secondary analysis of data collected in a trial of neoadjuvant endocrine therapy, comparing letrozole versus tamoxifen, found that response rate was significantly higher for letrozole compared with tamoxifen in the subgroup of patients with EGFR- and/or ErbB-2-positive tumors (88 versus $21 \% ; P=0.0004$ ). Furthermore, ErbB-2-positive tamoxifen-treated tumors exhibited a lower response rate than ErbB-2-negative tamoxifentreated tumors ( 17 versus $40 \% ; P=0.045$ ). In contrast, the response to the AI was not significantly influenced by ErbB-2 status, with response rates of $53 \%$ for ErbB-2-negative tumors and 69\% for ErbB-2-positive tumors. Unfortunately the relatively small sample size means that these results are not conclusive.

In conclusion, although a general consensus has not yet been reached, the prevalent message coming from these studies is that ErbB-2-positive patients may show resistance to treatment with tamoxifen but not with AIs. Consistent with this hypothesis, the majority of panelists involved in the last St Gallen Consensus Conference agreed to take ErbB-2 status into account when choosing endocrine treatment.

\section{Integration of endocrine therapy and signal transduction inhibitors}

Since increased growth factor signaling is involved in both de novo and acquired resistance of breast cancer cells to endocrine therapy, the use of signal transduction inhibitors in the treatment of ER-positive patients represents one of the most promising therapeutic approaches. In this respect, drugs that are able to block the different signaling pathways involved in resistance to hormonal therapy (EGFR, ErbB-2, IGF-1R, ras/raf/MEK/MAPK, PI3K/AKT) are in advanced clinical development. The results of preclinical studies suggest that these drugs might be effective in both hormone-sensitive and hormone-resistant breast cancer patients. In fact, different reports have shown that additive or synergistic effects are obtained when ER-positive breast cancer cells are treated with a combination of endocrine therapy and signal transduction inhibitors. For example, additive or synergistic effects of farnesyl transferase inhibitors when combined with tamoxifen or AIs in ER-positive breast cancer cells have been demonstrated (Johnston et al. 2002, Ellis et al. 2003, Long et al. 2004b). Similar results were obtained with combinations of mammalian target of rapamycin (mTOR) antagonists and estrogen deprivation therapy with letrozole in pre-clinical models (Rudloff et al. 2004). A synergistic anti-tumor effect has been reported for trastuzumab when combined with tamoxifen in ER-positive ErbB-2-overexpressing BT-474 breast cancer cells, although this combination did not induce apoptosis (Argiris et al. 2004). However, Ropero et al. (2004) found that this combination is additive at high levels of cell kills, whereas it is antagonistic at an effect level of $30 \%$ or lower. In addition, the efficacy of this combination was found to be dependent on the schedule of treatment, with simultaneous treatment yielding the highest anti-tumor activity. Finally, combined treatment of MCF-7 cells with tamoxifen and the EGFR-tyrosine kinase inhibitor gefitinib was more effective in inhibiting proliferation, promoting apoptosis and eliminating bcl-2 as compared with tamoxifen alone (Gee et al. 2003). Interestingly, combined treatment with gefitinib and tamoxifen prevented the occurrence of resistance to tamoxifen mediated by increased EGFR and MAPK signaling that is observed following treatment with tamoxifen alone. Taken together, these findings suggest that combinations of signal transduction inhibitors might be useful in upfront treatment of ER-positive breast cancer in order to improve the efficacy of hormonal therapy and to prevent the occurrence of resistance.

Signal transduction inhibitors also have a role in the treatment of hormone-resistant breast cancer. In fact, enhanced activity of anti-EGFR and anti-ErbB-2 agents in tamoxifen-resistant breast cancer cells has been previously demonstrated (Knowlden et al. 2003a). Furthermore, evidence suggests that in hormoneresistant cells combined treatment with signal transduction inhibitors and endocrine therapy may be more effective as compared to treatment with signal transduction inhibitors alone. For example, Carlos 
Arteaga's group reported that treatment of ErbB-2overexpressing tamoxifen-resistant MCF-7 cells with the ErbB-2 inhibitor AG1478 or the MAPK inhibitor U0126 restored the inhibitory effect of tamoxifen on ER-mediated transcription and cell proliferation (Kurokawa et al. 2000). More recently, Shou et al. (2004) have shown that treatment with gefitinib eliminated tamoxifen's agonist activity and restored its anti-tumor activity both in vitro and in vivo in ErbB2-overexpressing MCF-7 cells (MCF-7/HER2-18). In addition, by using the same in vivo model, Osborne's group demonstrated that gefitinib delays development of acquired resistance to estrogen deprivation in mice treated with gefitinib and estrogen withdrawal (Massarweh et al. 2002).

The above-mentioned pre-clinical findings led to the development of several clinical trials of combinations of endocrine therapy and signal transduction inhibitors in ER-positive breast cancer patients. The ongoing phase-II and -III clinical trials with such combinations have recently been reviewed in an exhaustive article by Stephen Johnston (2005). These trials employ combinations of trastuzumab, EGFR-tyrosine kinase inhibitors, farnesyl transferase inhibitors and mTOR inhibitors with either tamoxifen, AIs or fulvestrant. Some of these trials are in the post-tamoxifen setting, although randomized trials in patients that have not been pretreated with endocrine therapy are being conducted. More importantly, in two of these trials (the tamoxifen \pm gefitinib Astrazeneca 0225 phase-II trial and the letrozole \pm lapatinib GSK EGFR30008 phase-III study), biological studies have been undertaken with the aim of finding molecular markers that might predict response to therapy. Hopefully, these studies and additional studies of neoadjuvant therapy will provide important information for patient selection.

Encouraging preliminary results have recently been disclosed from a trial testing the combination of trastuzumab and letrozole in ErbB-2-positive and hormonal receptor-positive patients with advanced breast cancer (Wong et al. 2003, Ellis 2004). The majority of patients $(22 / 26)$ had received previous tamoxifen therapy in an adjuvant or metastatic setting. Treatment with trastuzumab and letrozole produced a complete response rate of $9 \%(2 / 22)$, with an overall objective response rate of $27 \%$ (complete and partial responses $4 / 22$ ) and a clinical benefit rate of $64 \%$ (complete and partial responses plus stable disease 14/22). Interestingly, all responding patients had remissions lasting longer than 1 year, with two patients having remission for more than 2 years. With a median follow-up of 70 weeks (range 12-170 weeks), the median time to disease progression was 31 weeks (range 15-47 weeks), and $43 \%$ of patients were free from progression at 1 year. However, a significant number of patients experienced early progressive disease, and this suggests overlapping resistance mechanisms. One suggested hypothesis is that defects in G1 checkpoint controls may determine a 'panresistance' to all anti-growth-factor strategies (Cariou et al. 2000).

More recently, results of a phase-II clinical trial of gefitinib versus gefitinib plus anastrozole have been published (Polychronis et al. 2005). As described above, combined treatment produced a more significant reduction of $\mathrm{Ki} 67$ labeling, as compared with gefitinib alone, in patients with ER-positive/EGFRpositive breast carcinoma.

Finally, an additional approach to treatment of endocrine-resistant breast cancer might be represented by the use of combinations of anti-EGFR and antiErbB-2 agents. In this regard, we have previously demonstrated that combined treatment of breast cancer cells that co-express EGFR and ErbB-2 with gefitinib plus trastuzumab results in a synergistic antitumor effect (Normanno et al. 2002). Similar findings were obtained by independent research groups (Moulder et al. 2001). Following these results, a phaseI/-II clinical trial of trastuzumab plus gefitinib in breast cancer patients with ErbB-2-expressing tumors has been completed (Arteaga et al. 2004). In the phase-I study, patients were treated with trastuzumab $(2 \mathrm{mg} / \mathrm{kg}$ per week) plus gefitinib at two dose levels: 250 and $500 \mathrm{mg} /$ day. At the highest dose, two out of three patients developed grade-3 diarrhoea. Therefore, the phase-II study was conducted using gefitinib at $250 \mathrm{mg}$ /day. Few responses were observed and only in previously untreated patients $(2 / 28)$, and time to progression appeared shorter than that previously reported with trastuzumab alone. These results led the investigators to conclude that further use of combinations of trastuzumab plus EGFR-tyrosine kinase inhibitors is not justified. However, we believe that the results of the phase-II study could have been flawed by the dose of gefitinib, which at $250 \mathrm{mg} /$ day is lower than the $500 \mathrm{mg} /$ day usually considered a full dose. In fact, equivalence of the 250 and $500 \mathrm{mg}$ doses has been suggested by phase-II trials of gefitinib in non-small-cell lung cancer, a disease where the majority of patients responding to gefitinib carry a mutation of the EGFR-tyrosine kinase domain associated with increased sensitivity to gefitinib. Since EGFR mutations have not been found in breast cancer, the $250 \mathrm{mg}$ dose could be too low to be active. This dose was chosen because of the unexpected 
toxicity observed at the $500 \mathrm{mg}$ level. However, a phase-I trial of the EGFR-tyrosine kinase inhibitor erlotinib plus standard-dose trastuzumab in women with ErbB-2-positive metastatic breast cancer yielded different results. Trastuzumab could be combined with $150 \mathrm{mg} /$ day erlotinib, the maximum tolerated dose of the drug, without significant diarrhea, and two partial responses were observed (Britten et al. 2004). Therefore, the full daily dose of erolotinib was chosen for a phase-II trial of this combination in breast cancer. Finally, grade- 3 diarrhea occurred in $10 \%$ of trastuzumab-resistant breast cancer patients treated with the dual EGFR/ErbB-2 inhibitor lapatinib, a frequency similar to that observed with pure EGFRtyrosine kinase inhibitors (Blackwell et al. 2004). Interestingly, 46 and $24 \%$ of the patients treated with lapatinib were progression-free at 8 and 16 weeks respectively following the start of the treatment (Blackwell et al. 2004). These findings suggest that the contemporary blockade of EGFR and ErbB-2 does not result in increased intestinal toxicity, and that chance could have played a relevant role in the toxicity observed by Arteaga et al. (2004). In addition, the above-mentioned preliminary results obtained with either the erlotinib plus trastuzumab combination or lapatinib suggest that this approach might result in significant anti-tumor activity in heavily pre-treated breast cancer patients.

\section{Conclusions and perspectives}

The above-mentioned findings demonstrate that a number of questions still need to be addressed in order to select the best therapeutic strategy in postmenopausal patients with ER-positive breast cancer in both advanced and adjuvant settings. In particular, current opinion for the majority of clinicians is that patients with advanced breast cancer should be treated with AIs as first-line treatment, since these drugs have shown higher activity and a better toxicity profile as compared with tamoxifen. However, the difference in terms of time to progression between tamoxifen and AIs is marginal. In addition, fulvestrant showed, at best, an efficacy similar to tamoxifen in previously untreated patients. These observations suggest that differences among these drugs in untreated advanced disease are not impressive. In other words, untreated breast cancer is a disease that is extremely sensitive to treatment with any hormonal drugs. Conversely, AIs and fulvestrant are active in a proportion of tamoxifen-resistant patients. According to our results, this observation might imply that long-term control of tumor growth could be obtained, in at least a proportion of patients, by using a sequence of tamoxifen, AIs and fulvestrant. In this respect, clinical data suggest that treatment with fulvestrant might either precede or follow AIs. Starting from the preclinical observations that we have summarized, the sequence AI-fulvestrant should be preferred, because treatment with fulvestrant might be associated with an increased incidence of development of an estrogenindependent phenotype. Of course, randomized clinical trials comparing different strategies are necessary to address these questions.

In the adjuvant setting, AIs have shown a greater efficacy as compared with tamoxifen, although longterm effects and toxicity have not been sufficiently studied yet. Positive results of clinical trials with AIs given after 2 or 5 years of treatment with tamoxifen are consistent with suggestions coming from the in vitro studies that we summarized in the above proposed model. In addition, the sequential schedule could also be convenient in terms of reduction of side effects and on economical grounds. However, it must be emphasized that head-to-head comparisons of sequential schedules with upfront AIs are needed in order to choose between the two strategies. In this regard, the biological characteristics of the tumor could be important in assisting the clinical decision. For example, they might be useful to identify patients at risk of early relapse, who might benefit from AIs as a first-line treatment. Finally, the widespread use of AIs in the adjuvant setting that is foreseen in the next few years implies that patients that will have tumor recurrence will be not suitable for treatment with such compounds. Therefore, the activity of fulvestrant and tamoxifen needs also to be addressed in patients with resistance to AIs.

It is likely that the next step in the development of novel therapeutic approaches for ER-positive patients is represented by the use of combinations of hormonal agents and signal transduction inhibitors. In this respect, preliminary results from clinical trials seem to indicate that ER-positive breast cancer is a more promising field for the development of such agents as compared with ER-negative patients. Indeed, activation of growth factor-driven signal transduction pathways is clearly involved in both de novo and acquired resistance to hormonal treatment. The role of these agents in the adjuvant setting needs to be explored. In particular, signal transduction inhibitors could increase the efficacy of endocrine therapy by preventing the occurrence of ER-negative tumors.

Finally, the knowledge of the molecular mechanisms involved in the suppression of ER expression and in 
the development of an ER-negative phenotype might allow novel therapeutic approaches in ER-negative patients. In fact, drugs potentially able to revert the mechanisms involved in the suppression of the expression of ER $\alpha$, such as HDAC inhibitors or demethylating agents, are currently in clinical trials. In this respect, studies in our laboratories are ongoing to assess whether induction of expression of ER $\alpha$ in breast cancer cells might at least in part restore an estrogen-dependent phenotype. In this respect, evidence also suggests that growth factor signaling is also involved in the suppression of $E R \alpha$ expression in breast cancer cells. Therefore, combinations of agents capable of inducing expression of ER $\alpha$ in ER-negative breast cancer cells, anti-estrogenic drugs and signal transduction inhibitors might represent a novel therapeutic approach in breast cancer patients. Such a combination of target-based agents might prove efficient in blocking tumor growth, allowing at least a delay in the need for chemotherapy in selected patients.

\section{Acknowledgements}

The following researchers of the NCI-Naples Breast Cancer Group also contributed to this manuscript. Cell Biology and Preclinical Models Unit: Amelia D’Alessio, Monica R. Maiello, Mario Mancino, Michele Grassi, Adele Carotenuto and Stefania Di Capua Ercolano. Clinical Trials Unit: Alessandro Morabito, Roberta D'Aniello and Gianfranco De Feo. Medical Oncology C Unit: Francesca Di Rella, Adriano Gravina, Vincenzo Labonia, Gabriella Landi, Francesco Nuzzo, Carmen Pacilio and Emanuela Rossi. Senology: Giuseppe D’Aiuto, Franca Avino, Immacolata Capasso, Claudio Longo, Michele Pizzorusso, Massimo Rinaldi and Renato Thomas. Radiotherapy: Brunello Morrica. Nuclear Medicine: Secondo Lastoria and Aldo Bartiromo. Pathology: Gerardo Botti, Maurizio Di Bonito, Antonio D'Antonio, Franca La Vecchia and Maria Staiano. Pharmacy: Maria Rosaria Salzano.

\section{Funding}

This work was in part supported by national and regional grants from the Associazione Italiana per la Ricerca sul Cancro (AIRC) to NN and FP and to the NOGEC (Naples Oncogenomic Center), and by grants from the Ministero della Salute, Ricerca Finalizzata FSN'04 to NN. The authors declare that there is no conflict of interest that would prejudice the impartiality of this scientific work.

\section{References}

Argiris A, Wang CX, Whalen SG \& DiGiovanna MP 2004 Synergistic interactions between tamoxifen and trastuzumab (Herceptin). Clinical Cancer Research 10 1409-1420.

Arpino G, Green SJ, Allred DC, Lew D, Martino S, Osborne CK \& Elledge RM 2004 HER-2 amplification, HER-1 expression, and tamoxifen response in estrogen receptor-positive metastatic breast cancer: a Southwest Oncology Group Study. Clinical Cancer Research 10 5670-5676.

Arteaga CL, O’Neil A, Moulder SL, Pins M, Sparano JA, Sledge GW \& Davidson NE 2004 ECOG1100: a phase I-II study of combined blockade of the erbB receptor network with trastuzmab and gefitinib ('Iressa') in patients (pts) with HER2-overexpressing metastatic breast cancer. Breast Cancer Research and Treatment $\mathbf{8 8}$ S1 S15-16 (abstract 25).

Atlas E, Cardillo M, Mehmi I, Zahedkargaran H, Tang C \& Lupu R 2003 Heregulin is sufficient for the promotion of tumorigenecity and metastasis of breast cancer in vivo. Molecular Cancer Resarch 1 165-175.

Bardou VJ, Arpino G, Elledge RM, Osborne CK \& Clark GM 2003 Progesterone receptor status significantly improves outcome prediction over estrogen receptor status alone for adjuvant endocrine therapy in two large breast cancer databases. Journal of Clinical Oncology 21 1973-1979.

Baum M, Budzar AU, Cuzick J, Forbes J, Houghton JH, Klijn JG \& Sahmoud T; ATAC Trialists' Group 2002 Anastrozole alone or in combination with tamoxifen versus tamoxifen alone for adjuvant treatment of postmenopausal women with early breast cancer: first results of the ATAC randomised trial. Lancet 359 2131-2139.

Benz CC, Scott GK, Sarup JC, Johnson RM, Tripathy D, Coronado E, Shepard HM \& Osborne CK 1993 Estrogendependent, tamoxifen-resistant tumorigenic growth of MCF-7 cells transfected with HER2/neu. Breast Cancer Research and Treatment 24 85-95.

Berry DA, Muss HB, Thor AD, Dressler L, Liu ET, Broadwater G, Budman DR, Henderson IC, Barcos M, Hayes D \& Norton L 2000 HER-2 and p53 expression vs. tamoxifen resistance in estrogen-receptor-positive node-positive breast cancer. Journal of Clinical Oncology 18 3471-3479.

Berstein LM, Wang JP, Zheng H, Yue W, Conaway M \& Santen RJ 2004 Long-term exposure to tamoxifen induces hypersensitivity to estradiol. Clinical Cancer Research 10 1530-1534.

BIG 1-98 Collaborative Group 2005 Letrozole versus tamoxifen as adjuvant endocrine therapy for postmenopausal women with receptor-positive breast cancer. BIG 1-98: a prospective randomized double-blind phase III study. Proceedings of the 9th International Conference, Primary Therapy of Early Breast Cancer, St Gallen, Switzerland. Abstract S4. 
Blackwell KL, Kaplan EH, Franco SX, Marcom PK, Maleski JE, Sorensen MJ \& Berger MS 2004 A phase II, open-label, multicenter study of GW572016 in patients with trastuzumab-refractory metastatic breast cancer. Proceedings of the American Society of Clinical Oncology 23196 (abstract 3006).

Boccardo F, Rubagotti A \& Amoroso D, on behalf of the Italian Tamoxifen Arimidex (ITA) trial 2003 Anastrozole appears to be superior to tamoxifen in women already receiving adjuvant tamoxifen treatment. Breast Cancer Research and Treatment $\mathbf{8 2}$ S6.

Bonneterre J, Thurlimann B, Robertson JF, Krzakowski M, Mauriac L, Koralewski P, Vergote I, Webster A, Steinberg M \& von Euler M 2000 Anastrozole versus tamoxifen as first-line therapy for advanced breast cancer in 668 postmenopausal women: results of the Tamoxifen or Arimidex Randomized Group Efficacy and Tolerability study. Journal of Clinical Oncology 18 3748-3757.

Britten CD, Pegram M, Rosen P, Finn RS, Wax A, Bosserman L, Gordon L, Lin LS, Mass R \& Slamon DJ 2004 Targeting ErbB receptor interactions: A phase I trial of trastuzumab and erlotinib in metastatic HER2+ breast cancer. Proceedings of the American Society of Clinical Oncology 23206 (abstract 3045).

Britton D, Hutcheson IR, Barrow D, McClelland RA \& Nicholson RI 2003 Estrogen receptor phosphorylation in hormone sensitive and anti-hormone resistant breast cancer cells. Breast Cancer Research and Treatment 82 S61.

Brodie A, Jelovac D, Macedo L, Sabnis G, Tilghman S \& Goloubeva O 2005 Therapeutic observations in MCF-7 aromatase xenografts. Clinical Cancer Research 11 884-888S.

Bunone G, Briand PA, Miksicek RJ \& Picard D 1996 Activation of the unliganded estrogen receptor by EGF involves the MAP kinase pathway and direct phosphorylation. EMBO Journal 15 2174-2183.

Buzdar AU, Jonat W, Howell A, Jones SE, Blomqvist CP, Vogel CL, Eiermann W, Wolter JM, Steinberg M, Webster A \& Lee D 1998 Anastrozole versus megestrol acetate in the treatment of postmenopausal women with advanced breast carcinoma: results of a survival update based on a combined analysis of data from two mature phase III trials. Arimidex Study Group. Cancer 83 1142-1152.

Buzdar A, Douma J, Davidson N, Elledge R, Morgan M, Smith R, Porter L, Nabholtz J, Xiang X \& Brady C 2001 Phase III, multicenter, double-blind, randomized study of letrozole, an aromatase inhibitor, for advanced breast cancer versus megestrol acetate. Journal of Clinical Oncology 19 3357-3366.

Campbell RA, Bhat-Nakshatri P, Patel NM, Constantinidou D, Ali S \& Nakshatri H 2001 Phosphatidylinositol 3-kinase/AKT-mediated activation of estrogen receptor alpha: a new model for anti-estrogen resistance. Journal of Biological Chemistry 276 9817-9824.
Cappelletti V, Celio L, Bajetta E, Allevi A, Longarini R, Miodini P, Villa R, Fabbri A, Mariani L, Giovanazzi R, Galante E, Greco M \& Daidone MG 2004 Prospective evaluation of estrogen receptor-beta in predicting response to neoadjuvant antiestrogen therapy in elderly breast cancer patients. Endocrine-Related Cancer 11 761-770.

Cariou S, Donovan JC, Flanagan WM, Milic A, Bhattacharya N \& Slingerland JM 2000 Down-regulation of p21WAF1/CIP1 or p27Kip1 abrogates antiestrogenmediated cell cycle arrest in human breast cancer cells. PNAS 97 9042-9046.

Carlomagno C, Perrone F, Gallo C, De Laurentiis M, Lauria R, Morabito A, Pettinato G, Panico L, D’Antonio A, Bianco AR \& De Placido S 1996 c-erb B2 overexpression decreases the benefit of adjuvant tamoxifen in early-stage breast cancer without axillary lymph node metastases. Journal of Clinical Oncology 14 2702-2708.

Chan CM, Martin LA, Johnston SR, Ali S \& Dowsett M 2002 Molecular changes associated with the acquisition of estrogen hypersensitivity in MCF-7 breast cancer cells on long-term estrogen deprivation. Journal of Steroid Biochemistry and Molecular Biology 81 333-341.

Chen JD \& Evans RM 1995 A transcriptional co-repressor that interacts with nuclear hormone receptors Nature 377 454-457.

Cheung KL, Robertson JF \& Scott N 2002 Endocrine response after prior treatment with fulvestrant ('Faslodex') in postmenopausal women with advanced breast cancer. European Journal of Cancer $38 \mathrm{~S} 98$.

Chung YL, Sheu ML, Yang SC, Lin CH \& Yen SH 2002 Resistance to tamoxifen-induced apoptosis is associated with direct interaction between Her2/neu and cell membrane estrogen receptor in breast cancer. International Journal of Cancer 97 306-312.

Clarke R, Brunner N, Katz D, Glanz P, Dickson RB, Lippman ME \& Kern FG 1989 The effects of a constitutive expression of transforming growth factor-alpha on the growth of MCF-7 human breast cancer cells in vitro and in vivo. Molecular Endocrinology 3 372-380.

Coombes RC, Hall E, Gibson LJ, Paridaens R, Jassem J, Delozier T, Jones SE, Alvarez I, Bertelli G, Ortmann O et al. 2004 A randomized trial of exemestane after two to three years of tamoxifen therapy in postmenopausal women with primary breast cancer. New England Journal of Medicine 350 1081-1092.

Cui X, Zhang P, Deng W, Oesterreich S, Lu Y, Mills GB \& Lee AV 2003 Insulin-like growth factor-I inhibits progesterone receptor expression in breast cancer cells via the phosphatidylinositol 3-kinase/Akt/mammalian target of rapamycin pathway: progesterone receptor as a potential indicator of growth factor activity in breast cancer. Molecular Endocrinology 17 575-588.

Davis T, Kennedy C, Chiew YE, Clarke CL \& deFazio A 2000 Histone deacetylase inhibitors decrease proliferation 
and modulate cell cycle gene expression in normal mammary epithelial cells. Clinical Cancer Research 6 4334-4342.

De Placido S, De Laurentiis M, Carlomagno C, Gallo C, Perrone F, Pepe S, Ruggiero A, Marinelli A, Pagliarulo C, Panico L et al. 2003 Twenty-year results of the Naples GUN randomized trial: predictive factors of adjuvant tamoxifen efficacy in early breast cancer. Clinical Cancer Research 9 1039-1046.

Dombernowsky P, Smith I, Falkson G, Leonard R, Panasci L, Bellmunt J, Bezwoda W, Gardin G, Gudgeon A, Morgan M et al. 1998 Letrozole, a new oral aromatase inhibitor for advanced breast cancer: double-blind randomized trial showing a dose effect and improved efficacy and tolerability compared with megestrol acetate. Journal of Clinical Oncology 16 453-461.

Dowsett M 2003 Analysis of time to recurrence in the ATAC (Arimidex, tamoxifen, alone or in combination) trial according to estrogen receptor and progesterone receptor status. Breast Cancer Research and Treatment 82 S7.

Dowsett M, Harper-Wynne C, Boeddinghaus I, Salter J, Hills M, Dixon M, Ebbs S, Gui G, Sacks N \& Smith I 2001 HER-2 amplification impedes the antiproliferative effects of hormone therapy in estrogen receptorpositive primary breast cancer. Cancer Research $\mathbf{6 1}$ 8452-8458.

Early Breast Cancer Trialist Group 1998 Tamoxifen for early breast cancer: an overview of the randomised trials. Lancet 351 1461-1467.

El-Ashry D, Miller DL, Kharbanda S, Lippman ME \& Kern FG 1997 Constitutive Raf-1 kinase activity in breast cancer cells induces both estrogen-independent growth and apoptosis. Oncogene 15 423-435.

Elledge RM, Green S, Ciocca D, Pugh R, Allred DC, Clark GM, Hill J, Ravdin P, O’Sullivan J, Martino S \& Osborne CK 1998 HER-2 expression and response to tamoxifen in estrogen receptor-positive breast cancer: a Southwest Oncology Group Study. Clinical Cancer Research 4 7-12.

Ellis CA, Vos MD, Wickline M, Riley C, Vallecorsa T, Telford WG, Zujewskil J, Clark GJ 2003 Tamoxifen and the farnesyl transferase inhibitor FTI-277 synergize to inhibit growth in estrogen receptor-positive breast tumor cell lines. Breast Cancer Research and Treatment $\mathbf{7 8}$ 59-67.

Ellis M 2004 Overcoming endocrine therapy resistance by signal transduction inhibition. Oncologist 9 20-26.

Ellis MJ, Coop A, Singh B, Mauriac L, Llombert-Cussac A, Janicke F, Miller WR, Evans DB, Dugan M, Brady C, Quebe-Fehling E \& Borgs M 2001 Letrozole is more effective neoadjuvant endocrine therapy than tamoxifen for ErbB-1- and/or ErbB-2-positive, estrogen receptorpositive primary breast cancer: evidence from a phase III randomized trial. Journal of Clinical Oncology 19 3808-3816.
Fallowfield L, Cella D, Cuzick J, Francis S, Locker G \& Howell A 2004 Quality of life of postmenopausal women in the Arimidex, Tamoxifen, Alone or in Combination (ATAC) Adjuvant Breast Cancer Trial. Journal of Clinical Oncology 22 4261-4271.

Fan M, Bigsby RM \& Nephew KP 2003 The NEDD8 pathway is required for proteasome-mediated degradation of human estrogen receptor (ER)-alpha and essential for the antiproliferative activity of ICI 182780 in ERalpha-positive breast cancer cells. Molecular Endocrinology 17 356-365.

Font de Mora J \& Brown M 2000 AIB1 is a conduit for kinase-mediated growth factor signaling to the estrogen receptor. Molecular and Cellular Biology 20 5041-5047.

Frasor J, Danes JM, Komm B, Chang KCN, Lyttle R \& Katzenellenbogen BS 2003 Profiling of estrogen upand down-regulated gene expression in human breast cancer cells: insights into gene networks and pathways underlying estrogenic control of proliferation and cell phenotype. Endocrinology 144 4562-4574.

Fuqua SA, Wiltschke C, Zhang QX, Borg A, Castles CG, Friedrichs WE, Hopp T, Hilsenbeck S, Mohsin S, O'Connell P \& Allred DC 2000 A hypersensitive estrogen receptor-alpha mutation in premalignant breast lesions. Cancer Research 60 4026-4029.

Gee JM, Robertson JF, Ellis IO \& Nicholson RI 2001 Phosphorylation of ERK1/2 mitogen-activated protein kinase is associated with poor response to antihormonal therapy and decreased patient survival in clinical breast cancer. International Journal of Cancer 95 247-254.

Gee JM, Harper ME, Hutcheson IR, Madden TA, Barrow D, Knowlden JM, McClelland RA, Jordan N, Wakeling AE \& Nicholson RI 2003 The antiepidermal growth factor receptor agent gefitinib (ZD1839/Iressa) improves antihormone response and prevents development of resistance in breast cancer in vitro. Endocrinology 144 5105-5117.

Goss PE, Ingle JN, Martino S, Robert NJ, Muss HB, Piccart MJ, Castiglione M, Tu D, Shepherd LE, Pritchard KI et al. 2003 A randomized trial of letrozole in postmenopausal women after five years of tamoxifen therapy for early-stage breast cancer. New England Journal of Medicine 349 1793-1802.

Goss PE, Ingle JN, Martino S, Robert NJ, Muss HB, Piccart MJ, Castiglione MM, Tu D, Shepherd LE \& Pater JL 2004 Updated analysis of the NCIC CTG MA.17 randomized placebo $(\mathrm{P})$ controlled trial of letrozole (L) after five years of tamoxifen in postmenopausal women with early stage breast cancer Proceedings of the American Society of Clinical Oncology 23 (abstract 847).

Gottardis MM \& Jordan VC 1988 Development of tamoxifen-stimulated growth of MCF-7 tumors in athymic mice after long-term antiestrogen administration. Cancer Research 48 5183-5187. 
Gottardis MM, Jiang SY, Jeng MH, Jordan VC 1989 Inhibition of tamoxifen-stimulated growth of an MCF-7 tumor variant in athymic mice by novel steroidal antiestrogens. Cancer Research 49 4090-4093.

Gradishar WJ 2004 Tamoxifen - What next? Oncologist 9 378-384.

Gronemeyer H 1991 Transcription activation by estrogen and progesterone receptors. Annual Review of Genetics 25 89-123.

Gutierrez MC, Detre S, Johnston S, Mohsin SK, Shou J, Allred DC, Schiff R, Osborne CK \& Dowsett M 2005 Molecular changes in tamoxifen-resistant breast cancer: relationship between estrogen receptor, HER-2, and p38 mitogen-activated protein kinase. Journal of Clinical Oncology 23 2469-2476.

Hall JM \& McDonnell DP 1999 The estrogen receptor $\beta$-isoform $(\mathrm{ER} \beta)$ of the human estrogen receptor modulates $\mathrm{ER} \alpha$ transcriptional activity and is a key regulator of the cellular response to estrogens and antiestrogens. Endocrinology 140 5566-5578.

Herynk MH \& Fuqua SA 2004 Estrogen receptor mutations in human disease. Endocrine Reviews 25 869-898.

Horlein AJ, Naar AM, Heinzel T, Torchia J, Gloss B, Kurokawa R, Ryan A, Kamei Y, Soderstrom M, Glass CK et al. 1995 Ligand-independent repression by the thyroid hormone receptor mediated by a nuclear receptor co-repressor. Nature 377 397-404.

Houston SJ, Plunkett TA, Barnes DM, Smith P, Rubens RD \& Miles DW 1999 Overexpression of c-erbB2 is an independent marker of resistance to endocrine therapy in advanced breast cancer. British Journal of Cancer 79 1220-1226.

Howell A, DeFriend DJ, Robertson JF, Blamey RW, Anderson L, Anderson E, Sutcliffe FA \& Walton P 1996 Pharmacokinetics, pharmacological and anti-tumour effects of the specific anti-oestrogen ICI 182780 in women with advanced breast cancer. British Journal of Cancer 74 300-308.

Howell A, Robertson JF, Quaresma Albano J, Aschermannova A, Mauriac L, Kleeberg UR, Vergote I, Erikstein B, Webster A \& Morris C 2002 Fulvestrant, formerly ICI 182780 , is as effective anastrozole in postmenopausal women with advanced breast cancer progressing after prior endocrine treatment. Journal of Clinical Oncology 20 3396-3403.

Howell A, Robertson JF, Abram P, Lichinitser MR, Elledge R, Bajetta E, Watanabe T, Morris C, Webster A, Dimery I \& Osborne CK 2004 Comparison of fulvestrant versus tamoxifen for the treatment of advanced breast cancer in postmenopausal women previously untreated with endocrine therapy: a multinational, double-blind, randomized trial. Journal of Clinical Oncology 22 1605-1613.

Howell A, Cuzick J, Baum M, Buzdar A, Dowsett M, Forbes JF, Hoctin-Boes G, Houghton J, Locker GY \& Tobias JS; ATAC Trialists' Group 2005 Results of the ATAC (Arimidex, Tamoxifen, Alone or in Combination) trial after completion of 5 years' adjuvant treatment for breast cancer. Lancet 365 60-62.

Hutcheson IR, Knowlden JM, Madden TA, Barrow D, Gee JM, Wakeling AE \& Nicholson RI 2003 Estrogen receptor-mediated modulation of the EGFR/MAPK pathway in tamoxifen-resistant MCF-7 cells. Breast Cancer Research and Treatment 81 81-93.

Hutcheson IR, Knowlden JM, Barrow D \& Nicholson RI 2004 IGF-1R/EGFR crosstalk in tamoxifen resistant MCF-7 breast cancer cells. Proceedings of the American Association for Cancer Research 455189.

Ingle JN, Rowland KM, Suman VJ, Mirchandani D, Bernath AM, Camoriano JK \& Perez EA 2004 Evaluation of fulvestrant in women with advanced breast cancer and progression on prior aromatase inhibitor therapy: a phase II trial of the North Central Cancer Treatment Group. Breast Cancer Research and Treatment 88 S38.

Jakesz R, Kaufmann M, Gnant M, Jonat W, Mittlboeck M, Greil R, Tausch C, Hilfrich J, Kwasny W \& Samonigg H 2004 Benefits of switching postmenopausal women with hormone-sensitive early breast cancer to anastrozole after 2 years adjuvant tamoxifen: combined results from 3123 women enrolled in the ABCSG Trial and the ARNO 95 Trial. Breast Cancer Research and Treatment 88 S7.

Joel PB, Smith J, Sturgill TW, Fisher TL, Blenis J \& Lannigan DA 1998 pp90rsk1 regulates estrogen receptormediated transcription through phosphorylation of Ser-167. Molecular and Cellular Biolology 18 1978-1984.

Johnston SR 2005 Combinations of endocrine and biological agents: present status of therapeutic and presurgical investigations. Clinical Cancer Research 11 889-899s.

Johnston SR \& Dowsett M 2003 Aromatase inhibitors for breast cancer: lessons from the laboratory. Nature Reviews Cancer 3 821-831.

Johnston SR, Saccani-Jotti G, Smith IE, Salter J, Newby J, Coppen M, Ebbs SR \& Dowsett M 1995 Changes in estrogen receptor, progesterone receptor, and $\mathrm{pS} 2$ expression in tamoxifen-resistant human breast cancer. Cancer Research 55 3331-3338.

Johnston SRD, Head JE, Valenti MR, Detre S, Brunton LA, De Rienzo A, Howes AJ, End D, Kaye S \& Dowsett M 2002 Endocrine therapy combined with the farnesyl transferase inhibitor (FTI) R115777 produces enhanced tumor growth inhibition in hormone-sensitive MCF-7 human breast cancer xenografts in vivo. Breast Cancer Research and Treatment 76 A245.

Jordan NJ, Gee JM, Barrow D, Wakeling AE \& Nicholson RI 2004 Increased constitutive activity of PKB/Akt in tamoxifen resistant breast cancer $\mathrm{MCF}-7$ cells. Breast Cancer Research and Treatment 87 167-180.

Kahlert S, Nuedling S, van Eickels M, Vetter H, Meyer R \& Grohe C 2000 Estrogen receptor alpha rapidly activates the IGF-1 receptor pathway. Journal of Biological Chemistry 275 18447-18453.

Kato S, Endoh H, Masuhiro Y, Kitamoto T, Uchiyama S, Sasaki H, Masushige S, Gotoh Y, Nishida E, Kawashima 
H, Metzger D \& Chambon P 1995 Activation of the estrogen receptor through phosphorylation by mitogenactivated protein kinase. Science 270 1491-1494.

Kaufmann M, Bajetta E, Dirix LY, Fein LE, Jones SE, Zilembo N, Dugardyn JL, Nasurdi C, Mennel RG, Cervek J, Fowst C, Polli A, di Salle E, Arkhipov A, Piscitelli G, Miller LL \& Massimini G 2000 Exemestane is superior to megestrol acetate after tamoxifen failure in postmenopausal women with advanced breast cancer: results of a phase III randomized double-blind trial. The Exemestane Study Group. Journal of Clinical Oncology 18 1399-1411.

Knoop AS, Bentzen SM, Nielsen MM, Rasmussen BB \& Rose C 2001 Value of epidermal growth factor receptor, HER2, p53, and steroid receptors in predicting the efficacy of tamoxifen in high-risk postmenopausal breast cancer patients. Journal of Clinical Oncology 19 3376-3384.

Knowlden JM, Hutcheson IR, Jones HE, Madden T, Gee JM, Harper ME, Barrow D, Wakeling AE \& Nicholson RI 2003a Elevated levels of epidermal growth factor receptor/c-erbB2 heterodimers mediate an autocrine growth regulatory pathway in tamoxifenresistant MCF-7 cells. Endocrinology 144 1032-1044.

Knowlden JM, Hutcheson IR, Barrow D \& Nicholson RI $2003 b$ IGF-1R and EGFR crosstalk in tamoxifen resistant breast cancer cells. Breast Cancer Research and Treatment 82 S171.

Kurokawa H, Lenferink AE, Simpson JF, Pisacane PI, Sliwkowski MX, Forbes JT \& Arteaga CL 2000 Inhibition of HER2/neu (erbB-2) and mitogenactivated protein kinases enhances tamoxifen action against HER2-overexpressing, tamoxifen-resistant breast cancer cells. Cancer Research 60 5887-5894.

Kushner PJ, Agard DA, Greene GL, Scanlan TS, Shiau AK, Uht RM \& Webb P 2000 Estrogen receptor pathways to AP-1. Journal of Steroid Biochemistry and Molecular Biology 74 311-317.

Lavinsky RM, Jepsen K, Heinzel T, Torchia J, Mullen TM, Schiff R, Del-Rio AL, Ricote M, Ngo S, Gemsch J, Hilsenbeck SG, Osborne CK, Glass CK, Rosenfeld MG \& Rose DW 1998 Diverse signaling pathways modulate nuclear receptor recruitment of N-CoR and SMRT complexes. PNAS 95 2920-2925.

Leo C \& Chen JD 2000 The SRC family of nuclear receptor coactivators. Gene 245 1-11.

Levin ER 2003 Bidirectional signaling between the estrogen receptor and the epidermal growth factor receptor. Molecular Endocrinology 17 309-317.

Lipton A, Ali SM, Leitzel K, Demers L, Harvey HA, Chaudri-Ross HA, Brady C, Wyld P \& Carney W 2003 Serum HER-2/neu and response to the aromatase inhibitor letrozole versus tamoxifen. Journal of Clinical Oncology 21 1967-1972.

Liu Y, El-Ashry D, Chen D, Ding IY \& Kern FG 1995 MCF-7 breast cancer cells overexpressing transfected c-erbB-2 have an in vitro growth advantage in estrogen-depleted conditions and reduced estrogen dependence and tamoxifen-sensitivity in vivo. Breast Cancer Research and Treatment 34 97-117.

Long BJ, Jelovac D, Thiantanawat A \& Brodie AM 2002 The effect of second-line antiestrogen therapy on breast tumor growth after first-line treatment with the aromatase inhibitor letrozole: long-term studies using the intratumoral aromatase postmenopausal breast cancer model. Clinical Cancer Research 8 2378-2388.

Long BJ, Jelovac D, Handratta V, Thiantanawat A, MacPherson N, Ragaz J, Goloubeva OG \& Brodie AM $2004 a$ Therapeutic strategies using the aromatase inhibitor letrozole and tamoxifen in a breast cancer model. Journal of the National Cancer Institute $\mathbf{9 6}$ 456-465.

Long BJ, Liu G, Marrinan CH, Maxwell E, Black S, Gheyas F, Nomeir A, Liu M, Kirschmeier P \& Bishop WR $2004 b$ Combining the farnesyl transferase inhibitor (FTI) Lonafarnib (SCH66336) with antiestrogens and aromatase inhibitors results in enhanced growth inhibition of hormone-dependent human breast cancer cells and tumor xenografts. Proceedings of the American Association for Cancer Research 45 A3868.

Lonning PE 2004 Aromatase inhibitors in breast cancer. Endocrine-Related Cancer 11 179-189.

Macaluso M, Cinti C, Russo G, Russo A \& Giordano A 2003 pRb2/p130-E2F4/5-HDAC1-SUV39H1-p300 and pRb2/p130-E2F4/5-HDAC1-SUV39H1-DNMT1 multimolecular complexes mediate the transcription of estrogen receptor-alpha in breast cancer. Oncogene 22 3511-3517.

McClelland RA, Barrow D, Madden TA, Dutkowski CM, Pamment J, Knowlden JM, Gee JM \& Nicholson RI 2001 Enhanced epidermal growth factor receptor signaling in MCF-7 breast cancer cells after long-term culture in the presence of the pure antiestrogen ICI 182780 (Faslodex). Endocrinology 142 2776-2788.

McDonnell DP 2005 The molecular pharmacology of estrogen receptor modulators: implications for the treatment of breast cancer. Clinical Cancer Research $\mathbf{1 1}$ 871-877s.

McDonnel DP, Clemm DL, Hermann T, Goldman ME \& Pike JW 1995 Analysis of estrogen receptor function in vitro reveals three distinct classes of antiestrogens. Molecular Endocrinology 9 659-669.

McKenna NJ, Lanz RB \& O’Malley BW 1999 Nuclear receptor coregulators: cellular and molecular biology. Endocrine Reviews 20 321-344.

Martin LA, Farmer I, Johnston SR, Ali S, Marshall C \& Dowsett M 2003 Enhanced estrogen receptor (ER) alpha, ERBB2, and MAPK signal transduction pathways operate during the adaptation of MCF-7 cells to long term estrogen deprivation. Journal of Biological Chemistry 278 30458-30468.

Martin MB, Garcia-Morales P, Stoica A, Solomon HB, Pierce M, Katz D, Zhang S, Danielsen M \& Saceda M 1995 Effects of 12-O-tetradecanoilphorbol-13-acetate 
on estrogen receptor activity in MCF-7 cells. Journal of Biological Chemistry $27025244-25251$.

Masamura S, Santner SJ, Heitjan DF \& Santen RJ 1995 Estrogen deprivation causes estradiol hypersensitivity in human breast cancer cells. Journal of Clinical Endocrinology and Metabolism 80 2918-2925.

Massarweh S, Shou J, Mohsin SK, Ge M, Wakeling AE, Osborne CK \& Schiff R 2002 Inhibition of epidermal growth factor/HER2 receptor signaling using ZD1839 ('Iressa') restores tamoxifen sensitivity and delays resistance to estrogen deprivation in HER2overexpressing breast tumors. Proceedings of the American Society of Clinical Oncology 21 (abstract 130).

Migliaccio A, Di Domenico M, Castoria G, de Falco A, Bontempo P, Nola E \& Auricchio F 1996 Tyrosine kinase/p21ras/MAP-kinase pathway activation by estradiol-receptor complex in MCF-7 cells. EMBO Journal 15 1292-1300.

Moulder SL, Yakes FM, Muthuswamy SK, Bianco R, Simpson JF \& Arteaga CL 2001 Epidermal growth factor receptor (HER1) tyrosine kinase inhibitor ZD1839 (Iressa) inhibits HER2/neu (erbB2)-overexpressing breast cancer cells in vitro and in vivo. Cancer Research $618887-8895$.

Mouridsen H, Gershanovich M, Sun Y, Perez-Carrion R, Boni C, Monnier A, Apffelstaedt J, Smith R, Sleeboom HP, Jaenicke F, Pluzanska A, Dank M, Becquart D, Bapsy PP, Salminen E, Snyder R, Chaudri-Ross H, Lang R, Wyld P \& Bhatnagar A 2003 Phase III study of letrozole versus tamoxifen as first-line therapy of advanced breast cancer in postmenopausal women: analysis of survival and update of efficacy from the International Letrozole Breast Cancer Group. Journal of Clinical Oncology 21 2101-2109.

Mueller H, Kueng W, Schoumacher F, Herzer S \& Eppenberger U 1995 Selective regulation of steroid receptor expression in $\mathrm{MCF}-7$ breast cancer cells by a novel member of the heregulin family. Biochemical and Biophysical Research Communications 217 1271-1278.

Nabholtz JM, Buzdar A, Pollak M, Harwin W, Burton G, Mangalik A, Steinberg M, Webster A \& von Euler M 2000 Anastrozole is superior to tamoxifen as first-line therapy for advanced breast cancer in postmenopausal women: results of a North American multicenter randomized trial. Arimidex Study Group. Journal of Clinical Oncology 18 3758-3767.

Nicholson RI, Staka C, Boyns F, Hutcheson IR \& Gee JM 2004 Growth factor-driven mechanisms associated with resistance to estrogen deprivation in breast cancer: new opportunities for therapy. Endocrine-Related Cancer 11 623-641.

Normanno N, Qi CF, Gullick WJ, Persico G, Yarden Y, Wen D, Plowman G, Kenney N, Johnson G, Kim N, Brandt R \& Salomon DS 1993 Expression of amphiregulin, cripto-1 and heregulin- $\alpha$ in human breast cancer cell lines. International Journal of Oncology 2 903-911.
Normanno N, Ciardiello F, Brandt R \& Salomon DS 1994 Epidermal growth factor-related peptides in the pathogenesis of human breast cancer. Breast Cancer Research and Treatment 29 11-27.

Normanno N, Campiglio M, De Luca A, Somenzi G, Maiello M, Ciardiello F, Gianni L, Salomon DS \& Menard S 2002 Cooperative inhibitory effect of ZD1839 (Iressa) in combination with trastuzumab (Herceptin) on human breast cancer cell growth. Annals of Oncology 13 65-72.

Normanno N, De Luca A, Bianco C, Maiello MR, Carriero MV, Rehman A, Wechselberger C, Arra C, Strizzi L, Sanicola M \& Salomon DS 2004a Cripto-1 overexpression leads to enhanced invasiveness and resistance to anoikis in human MCF-7 breast cancer cells. Journal of Cellular Physiology 198 31-39.

Normanno N, Maiello MR, Mancino M \& De Luca A $2004 b$ Small molecule epidermal growth factor receptor tyrosine kinase inhibitors: an overview. Journal of Chemotherapy 16 (Suppl 4) 36-40.

Oh AS, Lorant LA, Holloway JN, Miller DL, Kern FG \& El-Ashry D 2001 Hyperactivation of MAPK induces loss of ERalpha expression in breast cancer cells. Molecular Endocrinology 15 1344-1359.

Osborne CK \& Schiff R 2005 Estrogen-receptor biology: continuing progress and therapeutic implications. Journal of Clinical Oncology 23 1616-1622.

Osborne CK, Coronado E, Allred DC, Wiebe V \& DeGregorio M 1991 Acquired tamoxifen resistance: correlation with reduced breast tumor levels of tamoxifen and isomerization of trans-4-hydroxytamoxifen. Journal of the National Cancer Institute 83 1477-1482.

Osborne CK, Jarman M, McCague R, Coronado EB, Hilsenbeck SG, Wakeling AE 1994 The importance of tamoxifen metabolism in tamoxifen-stimulated breast tumor growth. Cancer Chemotherapy and Pharmacology 34 89-95.

Osborne CK, Schiff R, Fuqua SA \& Shou J 2001 Estrogen receptor: current understanding of its activation and modulation. Clinical Cancer Research 7 4338-4342s.

Osborne CK, Pippen J, Jones SE, Parker LM, Ellis M, Come S, Gertler SZ, May JT, Burton G, Dimery I, Webster A, Morris C, Elledge R \& Buzdar A 2002 Double-blind, randomized trial comparing the efficacy and tolerability of fulvestrant versus anastrozole in postmenopausal women with advanced breast cancer progressing on prior endocrine therapy: results of a North American trial. Journal of Clinical Oncology 20 3386-3395.

Osborne CK, Bardou V, Hopp TA, Chamness GC, Hilsenbeck SG, Fuqua SA, Wong J, Allred DC, Clark GM \& Schiff R 2003 Role of the estrogen receptor coactivator AIB1 (SRC-3) and HER-2/neu in tamoxifen resistance in breast cancer. Journal of the National Cancer Institute 95 353-361.

Osborne CK, Shou J, Massarweh S \& Schiff R 2005 Crosstalk between estrogen receptor and growth factor 
receptor pathways as a cause for endocrine therapy resistance in breast cancer. Clinical Cancer Research $\mathbf{1 1}$ 865-870s.

Ottaviano YL, Issa JP, Parl FF, Smith HS, Baylin SB \& Davidson NE 1994 Methylation of the estrogen receptor gene $\mathrm{CpG}$ island marks loss of estrogen receptor expression in human breast cancer cells. Cancer Research $542552-2555$.

Paech K, Webb P, Kuiper GG, Nilsson S, Gustafsson J, Kushner PJ \& Scanlan TS 1997 Differential ligand activation of estrogen receptors ERalpha and ERbeta at AP-1 sites. Science 277 1508-1510.

Paridaens R, Therasse P, Dirix L, Beex L, Piccart M, Cameron D, Cufer T, Roozendaal K, Nooij M \& Mattiacci MR 2004 First line hormonal treatment (HT) for metastatic breast cancer (MBC) with exemestane (E) or tamoxifen (T) in postmenopausal patients (pts) - A randomized phase III trial of the EORTC Breast Group. Proceedings of the American Society of Clinical Oncology 23 (abstract 515).

Parl FF 2003 Multiple mechanisms of estrogen receptor gene repression contribute to ER-negative breast cancer Pharmacogenomics Journal 3 251-253.

Perey L, Paridaens R, Nolè F, Pagani O, Bonnefoi H, Aebi S, Dietrich D, Goldhirsch A \& Thurlimann B 2004 Fulvestrant (FaslodexTM) as hormonal treatment in postmenopausal patients with advanced breast cancer progressing after treatment with tamoxifen and aromatase inhibitors: update of a phase II SAKK trial. Breast Cancer Research and Treatment 88 S236.

Perez-Tenorio G \& Stal O; Southeast Sweden Breast Cancer Group 2002 Activation of AKT/PKB in breast cancer predicts a worse outcome among endocrine treated patients. British Journal of Cancer 86 540-545.

Pettersson K, Delaunay F \& Gustafsson JA 2000 Estrogen receptor $\beta$ acts as a dominant regulator of estrogen signalling. Oncogene 19 4970-4978.

Piccart M, Parker LM \& Pritchard KI 2003 Oestrogen receptor downregulation: an opportunity for extending the window of endocrine therapy in advanced breast cancer. Annals of Oncology 14 1017-1025.

Pietras RJ, Arboleda J, Reese DM, Wongvipat N, Pegram MD, Ramos L, Gorman CM, Parker MG, Sliwkowski MX \& Slamon DJ 1995 HER-2 tyrosine kinase pathway targets estrogen receptor and promotes hormoneindependent growth in human breast cancer cells. Oncogene 10 2435-2446.

Polychronis A, Sinnett HD, Hadjiminas D, Singhal H, Mansi JL, Shivapatham D, Shousha S, Jiang J, Peston D, Barrett N, Vigushin D, Morrison K, Beresford E, Ali S, Slade MJ \& Coombes RC 2005 Preoperative gefitinib versus gefitinib and anastrozole in postmenopausal patients with oestrogen-receptor positive and epidermal-growth-factor-receptor-positive primary breast cancer: a double-blind placebo-controlled phase II randomised trial. Lancet Oncology 6 383-391.
Ray P, Ghosh SK, Zhang DH \& Ray A 1997 Repression of interleukin-6 gene expression by 17 beta-estradiol: inhibition of the DNA-binding activity of the transcription factors NF-IL6 and NF-kappa B by the estrogen receptor. FEBS Letters 409 79-85.

Razandi M, Pedram A, Park ST \& Levin ER 2003 Proximal events in signaling by plasma membrane estrogen receptors. Journal of Biology Chemistry 278 2701-2712.

Ring A \& Dowsett M 2004 Mechanisms of tamoxifen resistance. Endocrine-Related Cancer 11 643-658.

Robertson JFR, Gutteridge E, Cheung KL, Owers R, Koehler M, Hamilton L, Gee J \& Nicholson RI $2003 a$ Gefitinib (ZD1839) is active in acquired tamoxifen (TAM)-resistant oestrogen receptor (ER)-positive and ER-negative breast cancer: results from a phase II study. Proceedings of the American Society for Clinical Oncology 227.

Robertson JF, Osborne CK, Howell A, Jones SE, Mauriac L, Ellis M, Kleeberg UR, Come SE, Vergote I, Gertler S et al. $2003 \mathrm{~b}$ Fulvestrant versus anastrozole for the treatment of advanced breast carcinoma in postmenopausal women: a prospective combined analysis of two multicenter trials. Cancer 98 229-238.

Robertson KD, Ait-Si-Ali S, Yokochi T, Wade PA, Jones PL \& Wolffe AP 2000 DNMT1 forms a complex with Rb, E2F1 and HDAC1 and represses transcription from E2F-responsive promoters. Nature Genetics 25 338-342.

Ropero S, Menendez JA, Vazquez-Martin A, Montero S, Cortes-Funes H \& Colomer R 2004 Trastuzumab plus tamoxifen: anti-proliferative and molecular interactions in breast carcinoma. Breast Cancer Research and Treatment 86 125-137.

Rountree MR, Bachman KE \& Baylin SB 2000 DNMT1 binds HDAC2 and a new co-repressor, DMAP1, to form a complex at replication foci. Nature Genetics $\mathbf{2 5}$ 269-277.

Rudloff J, Boulay A, Zumstein-Mecker S, Evans DB, O'Reilly T, Lane HA 2004 The mTOR pathway in estrogen response: a potential for combining the rapamycin derivative RAD001 with the aromatase inhibitor Letrozole (Femara) in breast carcinoma. Proceedings of the American Association for Cancer Research 45 A5619.

Saeki T, Cristiano A, Lynch MJ, Brattain M, Kim N, Normanno N, Kenney N, Ciardiello F \& Salomon DS 1991 Regulation by estrogen through the $5^{\prime}$-flanking region of the transforming growth factor alpha gene. Molecular Endocrinology 5 1955-1963.

Safe S 2001 Transcriptional activation of genes by 17 betaestradiol through estrogen receptor-Spl interactions. Vitamins and Hormones 62 231-252.

Salomon DS, Brandt R, Ciardiello F \& Normanno N 1995 Epidermal growth factor-related peptides and their receptors in human malignancies. Critical Reviews in Oncology and Hematology 19 183-232.

Santen RJ, Song RX, Zhang Z, Kumar R, Jeng MH, Masamura S, Yue W \& Berstein L 2003 Adaptive 
hypersensitivity to estrogen: mechanism for superiority of aromatase inhibitors over selective estrogen receptor modulators for breast cancer treatment and prevention. Endocrine-Related Cancer 10 111-130.

Schiff R, Massarweh S, Shou J \& Osborne CK 2003 Breast cancer endocrine resistance: how growth factor signaling and estrogen receptor coregulators modulate response. Clinical Cancer Research 9 447-454S.

Schiff R, Massarweh S, Shou J, Bharwani L, Mohsin SK \& Osborne CK 2004 Cross-talk between estrogen receptor and growth factor pathways as a molecular target for overcoming endocrine resistance. Clinical Cancer Research 10 331-336S.

Shiau AK, Barstad D, Loria PM, Cheng L, Kushner PJ, Agard DA \& Greene GL 1998 The structural basis of estrogen receptor/coactivator recognition and the antagonism of this interaction by tamoxifen. Cell 95 927-937.

Shou J, Massarweh S, Osborne CK, Wakeling AE, Ali S, Weiss H \& Schiff R 2004 Mechanisms of tamoxifen resistance: increased estrogen receptor-HER2/neu cross-talk in ER/HER2-positive breast cancer. Journal of the National Cancer Institute 96 926-935.

Song RX, Santen RJ, Kumar R, Adam L, Jeng MH, Masamura S \& Yue W 2002a Adaptive mechanisms induced by long-term estrogen deprivation in breast cancer cells. Molecular and Cellular Endocrinology 193 $29-42$.

Song RX, McPherson RA, Adam L, Bao Y, Shupnik M, Kumar R \& Santen RJ $2002 b$ Linkage of rapid estrogen action to MAPK activation by ERalpha-Shc association and Shc pathway activation. Molecular Endocrinology 16 116-127.

Song RX, Barnes CJ, Zhang Z, Bao Y, Kumar R \& Santen RJ 2004 The role of Shc and insulin-like growth factor 1 receptor in mediating the translocation of estrogen receptor alpha to the plasma membrane. PNAS $\mathbf{1 0 1}$ 2076-2081.

Speirs V, Malone C, Walton DS, Kerin MJ \& Atkin SL 1999 Increased expression of estrogen receptor beta mRNA in tamoxifen-resistant breast cancer patients. Cancer Research 59 5421-5424.

Stal O, Borg A, Ferno M, Kallstrom AC, Malmstrom P \& Nordenskjold B; South Sweden Breast Cancer Group. Southeast Sweden Breast Cancer Group 2000 ErbB2 status and the benefit from two or five years of adjuvant tamoxifen in postmenopausal early stage breast cancer. Annals of Oncology 11 1545-1550.

Stearns V, Johnson MD, Rae JM, Morocho A, Novielli A, Bhargava P, Hayes DF, Desta Z \& Flockhart DA 2003 Active tamoxifen metabolite plasma concentration after coadministration of tamoxifen and the selective serotonin reuptake inhibitor paroxetine. Journal of the National Cancer Institute 95 1758-1764.

Stoica A, Saceda M, Fakhro A, Salomon HB, Fenster BD \& Martin MB 1997 The role of transforming growth factor-beta in regulation of estrogen receptor expression in the MCF-7 breast cancer cell line. Endocrinology 138 1498-1505.

Stoica A, Saceda M, Fakhro A, Joyner M \& Martin MB $2000 a$ Role of insulin-like growth factor-I in regulating estrogen receptor-alpha gene expression. Journal of Cellular Biochemistry 76 605-614.

Stoica A, Saceda M, Doraiswamy VL, Coleman C \& Martin MB $2000 b$ Regulation of estrogen receptor-alpha gene expression by epidermal growth factor. Journal of Endocrinology 165 371-378.

Strasser-Weippl K \& Goss E 2005 Advances in adjuvant hormonal therapy for postmenopausal women. Journal of Clinical Oncology 23 1751-1759.

Sun M, Paciga JE, Feldman RI, Yuan Z, Coppola D, Lu YY, Shelley SA, Nicosia SV \& Cheng JQ 2001

Phosphatidylinositol-3-OH kinase (PI3K)/AKT2, activated in breast cancer, regulates and is induced by estrogen receptor alpha (ERalpha) via interaction between ERalpha and PI3K. Cancer Research 61 5985-5991.

Tang CK, Perez C, Grunt T, Waibel C, Cho C \& Lupu R 1996 Involvment of heregulin-beta 2 in the acquisition of the hormone-independent phenotype of breast cancer cells. Cancer Research 56 3350-3358.

Thurlimann BJ, Keshaviah A, Mouridsen H, Mauriac L, Forbes JF, Paridaens R, Castiglione-Gertsch M, Gelber RD, Smith I \& Goldhirsch A 2005 BIG 1-98: randomized double-blind phase III study to evaluate letrozole (L) vs. tamoxifen (T) as adjuvant endocrine therapy for postmenopausal women with receptor-positive breast cancer Proceedings of the American Society of Clinical Oncology 24 (abstract 511).

Tzukerman MT, Esty A, Santiso-Mere D, Danielian P, Parker MG, Stein RB, Pike JW \& McDonnell DP 1994 Human estrogen receptor transactivational capacity is determined by both cellular and promoter context and mediated by two functionally distinct intramolecular regions. Molecular Endocrinology 8 21-30.

Valverius EM, Velu T, Shankar V, Ciardiello F, Kim N \& Salomon DS 1990 Over-expression of the epidermal growth factor receptor in human breast cancer cells fails to induce an estrogen-independent phenotype. International Journal of Cancer 46 712-718.

Vergote I, Robertson JF, Kleeberg U, Burton G, Osborne CK \& Mauriac L; Trial 0020 Investigators; Trial 0021 Investigators 2003 Postmenopausal women who progress on fulvestrant ('Faslodex') remain sensitive to further endocrine therapy. Breast Cancer Research and Treatment 79 207-211.

Wegman P, Vainikka L, Stål O, Nordenskjöld B, Skoog L, Rutqvist LE \& Wingren S 2005 Genotype of metabolic enzymes and the benefit of tamoxifen in postmenopausal breast cancer patients. Breast Cancer Research 7 R284-290.

Weigel RJ \& deConinck EC 1993 Transcriptional control of estrogen receptor in estrogen receptor-negative breast carcinoma. Cancer Research 53 3472-3474. 
Wong CW, McNally C, Nickbarg E, Komm BS \& Cheskis BJ 2002 Estrogen receptor-interacting protein that modulates its nongenimic activity-crosstalk with Src/Erk phosphorylation cascade. PNAS 99 14783-14788.

Wong ZW, Isaacs C, Harris L \& Ellis MJ 2003 A phase II trial of letrozole and trastuzumab for ER and/or PgR and HER2 positive metastatic breast cancer. Breast Cancer Research and Treatment 82 S106.

Wright C, Nicholson S, Angus B, Sainsbury JR, Farndon J, Cairns J, Harris AL \& Horne CH 1992 Relationship between c-erbB-2 protein product expression and response to endocrine therapy in advanced breast cancer. British Journal of Cancer 65 118-121.

Yang X, Ferguson AT, Nass SJ, Phillips DL, Butash KA, Wang SM, Herman JG \& Davidson NE 2000 Transcriptional activation of estrogen receptor alpha in human breast cancer cells by histone deacetylase inhibition. Cancer Research 60 6890-6894.

Yang X, Phillips DL, Ferguson AT, Nelson WG, Herman JG \& Davidson NE 2001 Synergistic activation of functional estrogen receptor (ER)-alpha by DNA methyltransferase and histone deacetylase inhibition in human ER-alpha-negative breast cancer cells. Cancer Research 61 7025-7029.

Yao K, Lee ES, Bentrem DJ, England G, Schafer JI, O'Regan RM \& Jordan VC 2000 Antitumor action of physiological estradiol on tamoxifen-stimulated breast tumors grown in athymic mice. Clinical Cancer Research $\mathbf{6}$ 2028-2036.

Yue W, Wang JP, Conaway MR, Li Y \& Santen RJ 2003 Adaptive hypersensitivity following long-term estrogen deprivation: involvement of multiple signal pathways. Journal of Steroid Biochemistry and Molecular Biology 86 265-274. 
